January 2022

\title{
Animal Assisted Therapy for Older Adults in Aged Care Facilities: A Rapid Review
}

\author{
Mitchell A. Franklin \\ Charles Sturt University, mitchfranklin7@hotmail.com \\ Tracey Parnell \\ Charles Sturt University, tparnell@csu.edu.au \\ Natasha Versi \\ Charles Sturt University, natasha.versi@gmail.com \\ Rodney Pope \\ Charles Sturt University, rpope@csu.edu.au
}

Follow this and additional works at: https://nsuworks.nova.edu/ijahsp

Part of the Gerontology Commons, and the Occupational Therapy Commons

\section{Recommended Citation}

Franklin MA, Parnell T, Versi N, Pope R. Animal Assisted Therapy for Older Adults in Aged Care Facilities: A Rapid Review. The Internet Journal of Allied Health Sciences and Practice. 2022 Jan 03;20(1), Article 14.

This Literature Review is brought to you for free and open access by the College of Health Care Sciences at NSUWorks. It has been accepted for inclusion in Internet Journal of Allied Health Sciences and Practice by an authorized editor of NSUWorks. For more information, please contact nsuworks@nova.edu. 


\title{
Animal Assisted Therapy for Older Adults in Aged Care Facilities: A Rapid Review
}

\begin{abstract}
Purpose: Research has demonstrated the effectiveness of animal assisted therapy (AAT) for improving the mental health of older adults in residential care. The aim of this rapid review was to synthesise existing research evidence to determine the approaches that AAT should take to enhance outcomes for older adults living in residential care. Methods: A systematic literature search was conducted to identify studies published between 2009 and 2019 that investigated AAT and improvement in physical and/or psychosocial outcomes for adults aged over 65 years, living in residential care. Studies were critically appraised to determine methodological quality, key data were extracted, and a critical narrative synthesis was conducted to determine features of effective AAT intervention. Results: Eighteen studies were identified for inclusion in this review. All eligible studies utilised dogs for AAT. Nearly all studies found positive outcomes from the AAT; however, several features of AAT were associated with better outcomes. AAT was shown to be effective at improving depressive symptoms and socioemotional behaviours regardless of the frequencies, durations, and overall intervention periods employed. Participant quality of life only improved when AAT was conducted up to twice weekly. Physical interaction and combined physical interaction and walking were both associated with positive outcomes. The use of trained/certified therapy dogs was more likely to improve outcomes than using dogs with no reported training. Facilitators provided by AAT organisations, and facilitators with veterinary, nursing, or AAT training were associated with improved outcomes. Group AAT was associated with greater effectiveness than AAT conducted with individual participants. Studies where AAT was conducted in a combined indoor/outdoor or solely indoor setting appeared most likely to improve outcomes. Conclusion: AAT involving dogs was typically associated with positive outcomes for older adults living in residential care; however, some features of AAT were associated with better outcomes. To enhance outcomes, it is recommended that AAT be implemented in a group setting, include physical interaction or combined physical interaction, and walking, and be conducted by trained facilitators.
\end{abstract}

\section{Author Bio(s)}

Mitchell Franklin, BOccThy(Hons), graduated with a Bachelor of Occupational Therapy (Honours) from Charles Sturt University in 2020. Mitchell is beginning as a community occupational therapist and has worked in aged care and disability services. His current research interests include animal assisted therapy, community services, and aged care.

Rodney Pope, PhD, is Professor of Physiotherapy at Charles Sturt University, Australia, and has over 30 years of experience in physiotherapy practice, research and teaching. Rod has worked across a range of contexts in this time, including hospital, private practice, aged care, disability, occupational and higher education settings.

Natasha Versi, BOccThy(Hons), graduated with a Bachelor of Occupational Therapy (Honours) from Charles Sturt University in 2020, and has submitted her honours research article to the Journal of Aging Research. Her current research interests include healthy aging, implementation science, dual-task activities and disability.

Tracey Parnell, PhD, is the Discipline Lead, Occupational Therapy at Charles Sturt University, Australia. Tracey has almost 30 years of experience in occupational therapy practice, teaching and research. Her experience has been in a range of settings including hospital based practice, community based rehabilitation, occupational/vocational rehabilitation, and higher education.

\section{Acknowledgements}

I would like to thank my supervisors, Dr Tracey Parnell and Professor Rod Pope for their continuous 
guidance and support throughout the entirety of this review. I would like to thank Charles Sturt University for guiding my career and academic journey and providing the opportunity to complete a Bachelor of Occupational Therapy (Honours) I would like to acknowledge and thank Natasha Versi for her assistance in completing this systematic review. Specifically, her assistance with critical appraisal as a second appraiser was incredibly useful and appreciated. I would like to thank the aged care facility where I work for the inspiration to complete this topic of research. I would also like to acknowledge their support for allowing me to take my dog in to visit residents and see the joy on their faces when interacting with him. I would like to thank my mother, Jen Franklin, for her unending support throughout my life and my Honours university journey. I would also like to thank my partner, Sarah Murphy, for her ongoing support and guidance throughout my research, my degree and my life in general. 


\title{
IIIAHSP \\ The Internet Journal of Allied Health Sciences and Practice \\ Dedicated to allied health professional practice and education \\ Vol. 20 No. 1 ISSN 1540-580X
}

\section{Animal Assisted Therapy for Older Adults in Aged Care Facilities: A Rapid Review}

\author{
Mitchell A. Franklin \\ Tracey Parnell \\ Natasha Versi \\ Rodney Pope
}

Charles Sturt University

Australia

\begin{abstract}
Purpose: Research has demonstrated the effectiveness of animal assisted therapy (AAT) for improving the mental health of older adults in residential care. The aim of this rapid review was to synthesise existing research evidence to determine the approaches that AAT should take to enhance outcomes for older adults living in residential care. Methods: A systematic literature search was conducted to identify studies published between 2009 and 2019 that investigated AAT and improvement in physical and/or psychosocial outcomes for adults aged over 65 years, living in residential care. Studies were critically appraised to determine methodological quality, key data were extracted, and a critical narrative synthesis was conducted to determine features of effective AAT intervention. Results: Eighteen studies were identified for inclusion in this review. All eligible studies utilised dogs for AAT. Nearly all studies found positive outcomes from the AAT; however, several features of AAT were associated with better outcomes. AAT was shown to be effective at improving depressive symptoms and socioemotional behaviours regardless of the frequencies, durations, and overall intervention periods employed. Participant quality of life only improved when AAT was conducted up to twice weekly. Physical interaction and combined physical interaction and walking were both associated with positive outcomes. The use of trained/certified therapy dogs was more likely to improve outcomes than using dogs with no reported training. Facilitators provided by AAT organisations, and facilitators with veterinary, nursing, or AAT training were associated with improved outcomes. Group AAT was associated with greater effectiveness than AAT conducted with individual participants. Studies where AAT was conducted in a combined indoor/outdoor or solely indoor setting appeared most likely to improve outcomes. Conclusion: AAT involving dogs was typically associated with positive outcomes for older adults living in residential care; however, some features of AAT were associated with better outcomes. To enhance outcomes, it is recommended that AAT be implemented in a group setting, include physical interaction or combined physical interaction, and walking, and be conducted by trained facilitators.
\end{abstract}

Keywords: animal assisted therapy, older adults, elderly, aged care, nursing home, pet therapy 


\section{INTRODUCTION}

Animal Assisted Therapy (AAT) is becoming increasingly popular in Australia and internationally, particularly in aged care facilities such as nursing homes and residential care facilities. AAT is a goal directed intervention that uses animals to work with people to enhance physical and psychosocial capabilities within a therapeutic context over multiple sessions..$^{1-3}$ AAT provides meaningful interaction and therapeutic gains for individuals in aged care facilities. ${ }^{4}$ Research has demonstrated the effectiveness of AAT for improving the physical and psychosocial health of older adults in aged care facilities. ${ }^{3,5,6}$ Many different animals can be used in AAT including dogs, cats, birds, fish, and horses. ${ }^{7,8}$ AAT can be utilised within individualised or group settings. $.2,9,10$

AAT with older adults has been used in many different environments and contexts, including homes, communities, and aged care facilities. ${ }^{11-13} \mathrm{AAT}$ is appealing as many people, including older adults, strongly value interaction with friendly animals. ${ }^{14,15}$ This approach to therapy offers individuals companionship; companionship is particularly important for older adults as social disconnectedness and isolation have been found to negatively impact their health. 14,15

Research has demonstrated that AAT can impact many outcomes for older adults, including depressive symptoms, socioemotional behaviours, and quality of life (QOL).12,16,17 Depressive symptoms can include insomnia, anxiety, physical agitation, and irritation. ${ }^{18}$ Socioemotional behaviours can include emotion regulation, emotional problem solving, stress, emotion inhibition, and levels of interpersonal conflict. ${ }^{19,20} \mathrm{QOL}$ refers to an individual's perception of their physical health, psychological state, level of independence, personal relationships, and social support within a cultural and valued context.21 These outcomes are important to address because increased depressive symptoms, impaired socioemotional behaviours, and decreased QOL are commonly identified in older adults in aged care facilities.4,22

Although multiple reviews have investigated the benefits of AAT for older adults, existing reviews do not adequately synthesise research to determine effective AAT approach(es) for older adults in aged care facilities. ${ }^{4,20,23} \mathrm{~A}$ review focusing on these approaches offers practical merit and is important in informing decisions of health professionals seeking to implement AAT in aged care facilities. For the purposes of this review, older adults are defined as people aged 65 years and over; this definition is the same as that used in the literature appraised for this review. The aim of this rapid review was to synthesise existing research evidence to determine the approach(es) that AAT should take to provide positive outcomes for older adults who live in aged care facilities. Based on this overarching research aim, the following research questions were developed:

1. What intervention frequencies and durations support effective AAT with older adults in aged care facilities?

2. What types of animals are effective to use in AAT with older adults in aged care facilities?

3. What types of training support AAT facilitators to implement effective AAT with older adults in aged care facilities?

4. What environments or settings support the implementation of effective AAT with older adults in aged care facilities?

5. What forms of therapeutic activities and interactions support effective AAT with older adults in aged care facilities?

\section{METHODS}

A rapid review was conducted to address the research aim and associated questions. ${ }^{24}$ The Preferred Reporting Items for Systematic reviews and Meta-Analyses (PRISMA) checklist was employed to ensure optimal reporting of the rapid review.25 The System for the Unified Management, Assessment and Review of Information (SUMARI) was used to facilitate the review process for this research. ${ }^{26}$ This review was registered with the Prospective Register of Systematic reviews (PROSPERO) prior to the screening and selection process (receipt number 159185).

\section{Information Sources}

The following databases were chosen for searching as they are large databases that cover nursing and allied health research: Cumulative Index to Nursing and Allied Health Literature (CINAHL), EBSCOhost, Medline, OTseeker, Cochrane library and PEDro. Potentially relevant articles were also identified through searches of reference lists of included articles and by inputting included articles into Scopus, an abstract and citation database, to identify subsequent, citing articles.

\section{Search Strategy}

A preliminary search of PROSPERO, MEDLINE, the Cochrane Database of Systematic Reviews and the JBI Database of Systematic Reviews and Implementation Reports was conducted and no current or on-going systematic reviews on the topic were identified.

The text contained in the titles and abstracts of indexed articles, and the key terms used to describe the articles were searched using a tailored search strategy. The search strategy, including all identified keywords and index terms, was adapted for each information source. Table 1 provides an example of a search strategy. 
Table 1: Example search strategy for CINAHL

\begin{tabular}{|c|c|c|c|}
\hline Database & Search strings & Limiters/filters & $\begin{array}{c}\text { Search } \\
\text { date }\end{array}$ \\
\hline \multirow[t]{3}{*}{ CINAHL } & (MH "Pet Therapy+") AND (MH "Nursing Homes+") & $\begin{array}{l}\text { Articles published in } \\
\text { English } \\
\text { Published within the last } \\
10 \text { years }\end{array}$ & $11 / 12 / 19$ \\
\hline & $\begin{array}{l}\text { (MH "Aged, } 80 \text { and Over+") OR (MH "Aged+") AND (MH "Pet } \\
\text { Therapy+") AND (MH "Nursing Homes+") }\end{array}$ & $\begin{array}{l}\text { Articles published in } \\
\text { English } \\
\text { Published within the last } \\
10 \text { years }\end{array}$ & $11 / 12 / 19$ \\
\hline & $\begin{array}{l}\text { ("animal human bonding" OR "animal assisted" OR "companion animal" } \\
\text { OR "canine assisted" OR "dog assisted" OR "pet assisted" OR pet*) } \\
\text { AND (elderly OR "older adults" OR aged OR geriatric OR senior*) AND } \\
\text { (cogniti" OR psychological OR dementia OR Alzheimer* OR "functional } \\
\text { decline") AND ("nursing home*" OR "residential care" OR "aged care" } \\
\text { OR "care facilit") }\end{array}$ & $\begin{array}{l}\text { Articles published in } \\
\text { English } \\
\text { Published within the last } \\
10 \text { years }\end{array}$ & $11 / 12 / 19$ \\
\hline
\end{tabular}

\section{Study Selection}

Following the information source search, all identified citations were collated and uploaded into EndNote X8.2 2019 and duplicates were removed. ${ }^{27}$ One primary reviewer (M.F.) screened the titles and abstracts of articles against the eligibility criteria (Table 2) to determine if they were potentially eligible or whether they were clearly ineligible and should be excluded from further consideration.

The full texts of potentially relevant studies were retrieved, and the corresponding citation details were downloaded to EndNote X8.2 2019.27 The full texts of selected citations were assessed in detail against the eligibility criteria by one primary reviewer (M.F) to determine eligibility. The results of the search, screening and selection processes were documented using a Preferred Reporting Items for Systematic reviews and Meta-analyses (PRISMA) flow diagram. ${ }^{25}$

\section{Eligibility criteria}

Eligibility criteria for studies to be included in this review are presented in Table 2 below.

Table 2: Eligibility Criteria

\begin{tabular}{|c|c|c|}
\hline Eligibility Criteria & Inclusion & Exclusion \\
\hline i. Population, or participants & $\begin{array}{l}\text { Studies of people with a mean age of } 65 \\
\text { years or above living in aged care } \\
\text { facilities. }\end{array}$ & $\begin{array}{l}\text { Studies involving participants with a } \\
\text { mean age below } 65 \text { years and/or not } \\
\text { living in aged care facilities. }\end{array}$ \\
\hline $\begin{array}{l}\text { ii. Interventions or exposures - types of } \\
\text { interventions and intervention settings }\end{array}$ & $\begin{array}{l}\text { Studies of any AAT intervention or } \\
\text { combination of AAT interventions } \\
\text { conducted for the improvement of } \\
\text { physical and/or psychosocial outcomes. }\end{array}$ & \\
\hline iii. Comparisons or control groups & $\begin{array}{l}\text { Studies which have compared the use of } \\
\text { AAT with no AAT or with standard care } \\
\text { without AAT. This may include single } \\
\text { group pre-to-post comparison or may } \\
\text { involve comparison with a control group. }\end{array}$ & \\
\hline iv. Outcomes of interest & $\begin{array}{l}\text { Studies which report outcomes indicating } \\
\text { health status, including direct measures } \\
\text { of physical, emotional or social } \\
\text { wellbeing. }\end{array}$ & \\
\hline $\begin{array}{l}\text { v. Quality of intervention descriptions } \\
\text { and setting }\end{array}$ & $\begin{array}{l}\text { Studies which provide a full or partial } \\
\text { description of the AAT intervention } \\
\text { implemented that went further than just } \\
\text { stating the study involved AAT. The } \\
\text { intervention description was clearly } \\
\text { outlined so that practitioners would be } \\
\text { able to at least partially replicate the } \\
\text { interventions evaluated in the study. } \\
\text { Studies conducted in aged care facilities. }\end{array}$ & \\
\hline
\end{tabular}




\begin{tabular}{|c|c|c|}
\hline & & $\begin{array}{l}\text { Studies that have not been conducted in } \\
\text { aged care facilities }\end{array}$ \\
\hline vi. Study designs & $\begin{array}{l}\text { Quantitative randomised control trials } \\
\text { were the primary study design of interest } \\
\text { to include in this rapid review. It was } \\
\text { expected that there would be few } \\
\text { randomised control trials, thus studies of } \\
\text { quasi experimental design were included } \\
\text { provided they included suitable } \\
\text { comparison/s mentioned in section iii. } \\
\text { Inclusion of these additional study types } \\
\text { ensured that the best available evidence } \\
\text { was included in this review. }\end{array}$ & $\begin{array}{l}\text { Unpublished or non peer-reviewed } \\
\text { studies e.g. dissertations. } \\
\text { Studies with a qualitative design. } \\
\text { Studies that are not randomised } \\
\text { controlled trials or quasi experimental } \\
\text { studies by design. }\end{array}$ \\
\hline vii. Language of publication & & Studies not published in English \\
\hline
\end{tabular}

\section{Assessment of Methodological Quality}

Studies deemed eligible for inclusion within this review were placed into groups reflecting either randomised controlled trials (RCT) or quasi-experimental studies for critical appraisal. Studies were then critically appraised using the Randomised Controlled Trial and Quasi-Experimental critical appraisal tools developed by the Joanna Briggs Institute (JBI). ${ }^{28}$ In accordance with the critical appraisal tools, RCTs were given a score out of 13 and quasi experimental designs were scored out of nine. These scores were then converted to percentage scores.

Critical appraisal was completed by two independent reviewers. The second reviewer (N.V.) appraised six of the 18 studies, including three randomised controlled trials (RCTs) and three studies of quasi experimental design, to provide validation of appraisals conducted by the primary reviewer (M.F.), who appraised all 18 studies. Any differences between the two reviewers were resolved through discussion. Having two reviewers appraise the articles separately and then compare and discuss their appraisals increased the rigour of this study by reducing the risk of bias. ${ }^{29}$ Studies that received a score of less than $50 \%$ were appraised again by the primary reviewer. Studies that received a critical appraisal score of less than $50 \%$ on both the first and subsequent review were excluded from this review. As these studies were of a relatively low quality, it could not be guaranteed that they were rigorous enough to provide reliable or valid results to inform this review.

\section{Data Extraction}

Data extraction was conducted by the primary reviewer (M.F) following the critical appraisal of included studies. The extracted data were compiled into three tables; one table to summarise the characteristics and results of the studies reviewed, one to outline the AAT intervention details from each included study, and another to present the measured outcomes from each included study.

\section{Data Synthesis}

The analysis of data and synthesis of results were conducted using a critical narrative synthesis approach. Critical narrative synthesis involves the use of a word-based approach that enables investigation of similarities and differences between the included studies, exploration of relationships within the data, and assessment of the strength of the evidence provided by the included studies. ${ }^{30,31}$ To determine key features of effective AAT interventions, a critical narrative synthesis was conducted to explore the features of interest outlined previously: the frequency and duration of AAT; animals used; facilitator training; animal training/certification; environment/setting; and what therapeutic activities are included in AAT sessions. Critical narrative synthesis was used to explore and present the range of AAT approaches employed in the included studies and to demonstrate how these approaches contributed to effective outcomes. Critical narrative synthesis was appropriate to use in this review as it focused on a range of questions that are not just about the effectiveness of a particular intervention. ${ }^{32} \mathrm{~A}$ critical narrative synthesis of study findings can be used to holistically interpret the collected evidence when studies included are diverse in nature. ${ }^{31}$ Critical narrative synthesis results in a summary of knowledge related to the included research questions and this knowledge may be used to inform practice or policy. ${ }^{30}$

\section{RESULTS}

Figure 1 depicts the flow of information throughout the stages of this review. The initial database searches resulted in 561 articles. Another 29 articles were identified through additional sources, including searches of the reference lists of included studies. Following the removal of duplicates, 362 articles remained. Of these 362 articles, 326 were removed as these papers 
clearly did not meet the eligibility criteria following review of their titles and abstracts. The full texts of the remaining 36 articles were reviewed in greater detail and a further 18 were excluded in accordance with the eligibility criteria. The final number of included studies in this review was 18.
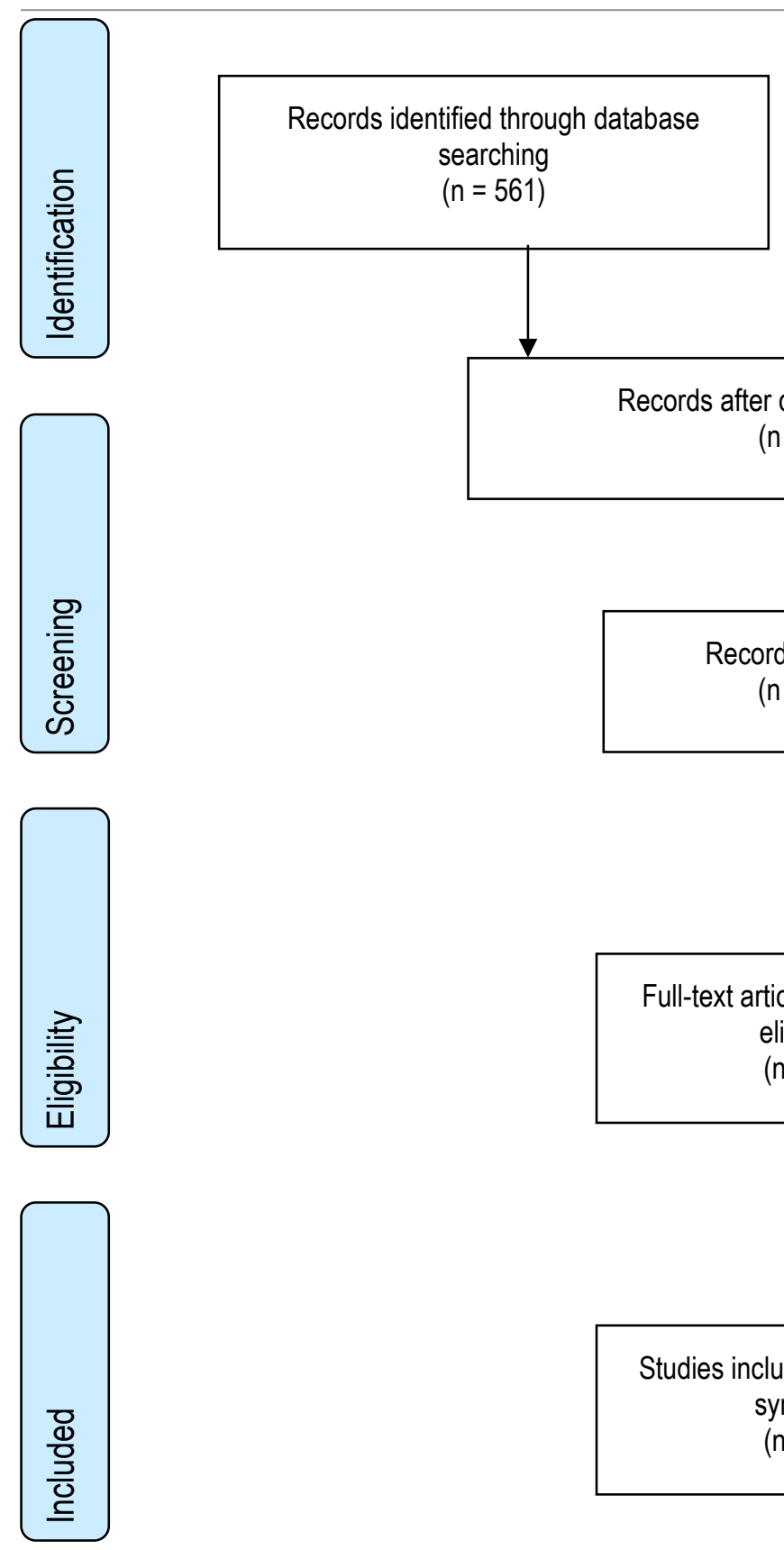

Additional records identified through other sources $(n=29)$

\section{Records after duplicates removed} $(n=362)$
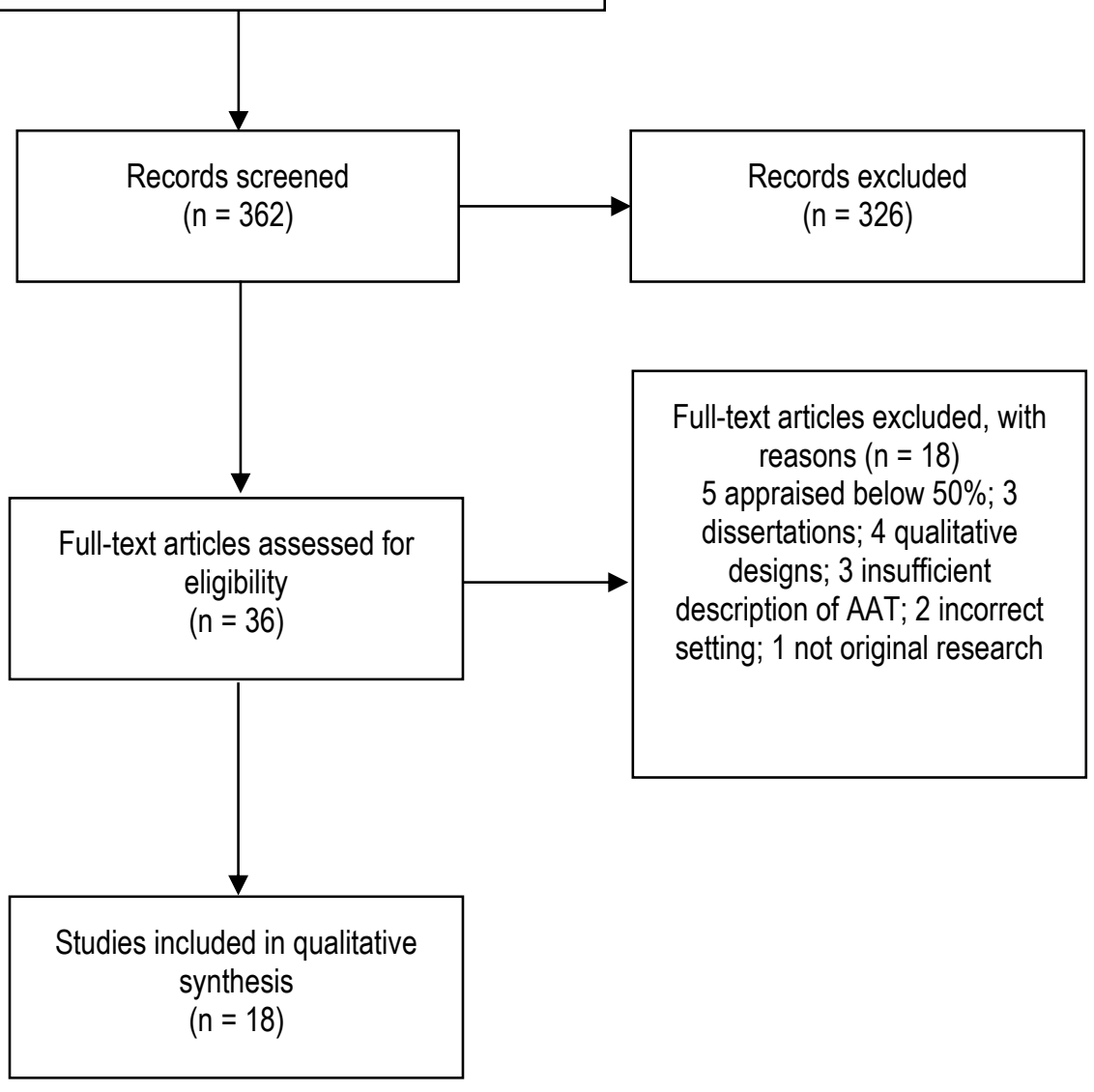

Full-text articles excluded, with reasons $(n=18)$ 5 appraised below $50 \%$; 3 dissertations; 4 qualitative designs; 3 insufficient description of AAT; 2 incorrect setting; 1 not original research

\section{FIGURE 1: PRISMA flowchart depicting results of screening and selection processes ${ }^{25}$}

\section{Critical Appraisal and Study Characteristics}

The critical appraisal scores of included studies ranged from $53 \%$ to $100 \%$ and are presented in Table 3, along with details for each study of study participants, the country and setting of each study, the outcome measures assessed, and reported outcomes. The average quality of included quasi experimental studies was higher than for the included RCTs. The mean critical appraisal score for the included RCTs was $8 / 13(61.5 \%)$. The mean critical appraisal score for included quasi experimental studies was $6 / 9(76.7 \%)$. Based on all the participant outcomes reported, the methodological quality of the included studies varied but did not appear to impact the reported outcomes.

Table 3 shows data relating to the author, year of publication, participant information, country and setting of study, outcome measures and reported outcomes. Of note, most of the included studies had relatively low numbers of participants within study 
groups and this will have affected the statistical power of each such study to detect small to moderate effects of AAT. Table 4 outlines data relating to the animals used in AAT, frequency and duration of AAT, facilitator training, animal training/certification, environment/setting, and the therapeutic activities performed within AAT sessions. The outcomes measured in the included studies are presented in Table 5; information regarding whether significant improvement, no improvement or significant worsening was found for each outcome is noted in this table. As noted above, the numbers of participants in the included studies were typically low and those low numbers will have reduced the statistical power of the studies. Therefore, it is possible that non-significant findings were due to low power rather than an actual absence of effect of AAT on specific outcomes. 
Table 3: Study Characteristics

\begin{tabular}{|c|c|c|c|c|}
\hline $\begin{array}{c}\text { Study author(s), } \\
\text { year, and critical } \\
\text { appraisal score }\end{array}$ & $\begin{array}{c}\text { Participants } \\
\text { Intervention group = IG } \\
\text { Control Group }=\text { CG }\end{array}$ & $\begin{array}{l}\text { Country and } \\
\text { setting of study }\end{array}$ & Outcome measures & Reported outcomes \\
\hline \multicolumn{5}{|c|}{ Randomised Controlled Trials } \\
\hline $\begin{array}{l}\text { (Ambrosi et al., } \\
2019)^{33} \\
7 / 1353.8 \%\end{array}$ & $\begin{array}{l}\mathrm{N}=31 \\
2 \mathrm{M} \& 29 \mathrm{~F} \\
\text { IG N }=17 \\
\mathrm{CG} N=14 \\
\text { IG mean age } 82.6 \\
\mathrm{CG} \text { mean age } 87.1\end{array}$ & $\begin{array}{ll}\text { - } & \text { Italy } \\
\text { - } & 1 \text { nursing } \\
& \text { home }\end{array}$ & $\begin{array}{ll}\text { - } & \text { GDS-15 } \\
\text { - } & \text { PANAS } \\
\text { - } & \text { GAD-7 } \\
\text { - } & \text { NPR } \\
\text { - } & \text { A Satisfaction Questionnaire }\end{array}$ & $\begin{array}{l}\text { Within AAT group comparison: } \\
\text { - } \quad \text { large }\left(d_{a v}=2.05\right) \text { decrease in GDS-15 scores following AAT }(p<.05) \\
\text { - The GAD-7 and PANAS scores did not change following AAT } \\
\text { - The IPQ-R and NPRS scores did not change following AAT } \\
\text { On a scale of } 1-5 \text {, the mean rating of satisfaction with AAT after weeks 3, 6, and } 9 \text { was } 4.89 \text {, } \\
\text { with all ratings being either } 4 \text { or } 5 \\
\text { Between group comparison: } \\
\text { - No differences were found in the net scores for the GDS-15, GAD-7 and PANAS. However, } \\
\text { further analysis revealed that the GDS-15 scores were lower in the IG compared with the CG, } \\
\text { with a large effect size }(p<.05) \\
\text { No difference in scores on the IPQ-R and NPRS }\end{array}$ \\
\hline $\begin{array}{l}(\text { Olsen et al., } \\
2016)^{22} \\
8 / 1361.53 \%\end{array}$ & $\begin{array}{l}\mathrm{N}=51 . \\
\text { IG N }=25,10 \mathrm{M} \& 15 \mathrm{~F} \\
\mathrm{CG} \mathrm{N}=26,9 \mathrm{M} \& 17 \mathrm{~F} \\
\text { IG mean age } 82.9 \\
\text { CG mean age } 84.1 \\
58 \text { residents were initially } \\
\text { recruited ( } 3 \text { IG and } 4 \mathrm{CG} \\
\text { participants withdrew) }\end{array}$ & 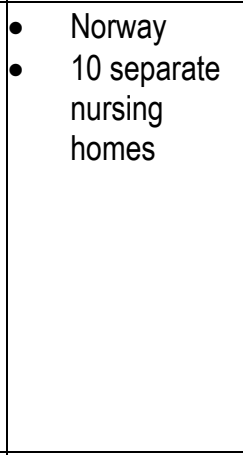 & $\begin{array}{ll}\text { - } & \text { CSDD } \\
\text { - } & \text { BARS } \\
& \text { QUALID (Norwegian version) }\end{array}$ & $\begin{array}{l}\text { Between group comparison: } \\
\text { The improvement in the CSDD scores from T1 to T3 was greater in the IG than in the CG ( } p< \\
\text {.05). This improvement was more evident in participants with severe dementia than those with } \\
\text { mild to moderate dementia. } \\
\text { Within AAT group comparison: } \\
\text { - No significant change in CSDD scores from T1 to T2. The change in CSDD scores from T1 to } \\
\text { T2 among participants with severe dementia was close to statistically significant }(p=.054) \\
\text { No significant effects on QOL in the total sample or in participants with mild to moderate } \\
\text { dementia. However, AAT improved QOL from T1 to T2 and T3 for participants with severe } \\
\text { dementia } \\
\text { No significant effects on agitation as measured by the BARS }\end{array}$ \\
\hline $\begin{array}{l}\left(\begin{array}{l}\text { Pope et al., } \\
2016)^{16} \\
7 / 1353.8 \%\end{array}\right.\end{array}$ & $\begin{array}{l}N=44 \\
20 \mathrm{M} \& 24 \mathrm{~F} \\
\text { Unclear number of participants } \\
\text { per group } \\
\text { Mean age } 79.8\end{array}$ & $\begin{array}{l}\text { USA } \\
1 \text { nursing } \\
\text { home }\end{array}$ & $\begin{array}{l}\text { - The Social Behaviours checklist } \\
\text { - } \\
\text { - } \\
\text { MPES }\end{array}$ & $\begin{array}{l}\text { Within group comparison: } \\
\text { Social Behavioural scores improved in both the AAT and human interaction }(\mathrm{HI}) \text { groups }(p<.05) \\
\text { Between group comparison: } \\
\text { - Scores on the Social Behaviours checklist were higher in the AAT group than the HI group }(p< \\
\text {.05) } \\
\text { No significant differences existed overall on the CMAI. However, during weeks of AAT, a lower } \\
\text { score on the screaming and verbal aggression item was noted for AAT participants }(p<.05) \\
\text { There was no significant difference in engagement levels between the AAT group and the HI } \\
\text { group } \\
\text { No significant differences between AAT and HI group scores on MPES }\end{array}$ \\
\hline
\end{tabular}




\begin{tabular}{|c|c|c|c|c|}
\hline $\begin{array}{c}\text { Study author(s), } \\
\text { year, and critical } \\
\text { appraisal score }\end{array}$ & $\begin{array}{c}\text { Participants } \\
\text { Intervention group = IG } \\
\text { Control Group = CG }\end{array}$ & $\begin{array}{l}\text { Country and } \\
\text { setting of study }\end{array}$ & Outcome measures & Reported outcomes \\
\hline $\begin{array}{l}\text { (Majic et al., } \\
2013)^{17} \\
9 / 1369.2 \%\end{array}$ & $\begin{array}{l}N=65 \\
18 \mathrm{M} \& 47 \mathrm{~F} \\
\text { IG N }=30 \\
\mathrm{CG} \mathrm{N}=35 \\
\text { Mean age } 81.7 \\
75 \text { residents were initially } \\
\text { recruited. There was equal } \\
\text { attrition in the IG and CG }\end{array}$ & 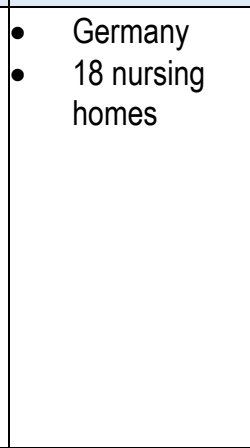 & $\begin{array}{ll}\text { - } & \text { CMAI } \\
& \text { DMAS }\end{array}$ & $\begin{array}{l}\text { Within AAT group comparison: } \\
\text { - Symptoms of agitation (CMAI) and depression (DMAS) improved from T1 to T2 in the IG by time } \\
\text { effect ( } p<.05) \\
\text { Between group comparison: } \\
\text { - Symptoms of agitation/aggression and depression increased in the CG from T1 to T2 }(p<.05) \text {, } \\
\text { while no change was found in the IG from T1 to T2 }\end{array}$ \\
\hline $\begin{array}{l}\text { (Briones et al., } \\
2019)^{34} \\
9 / 1369.2 \%\end{array}$ & $\begin{array}{l}N=34 \\
9 \mathrm{M} \& 25 \mathrm{~F} \\
\text { IG N }=16 \\
\mathrm{CG} \mathrm{N}=18 \\
\text { IG mean age } 89.3 \\
\text { CG mean age } 88.17 \\
39 \text { participants were initially } \\
\text { recruited. } 5 \text { withdrew from the } \\
\text { CG }\end{array}$ & 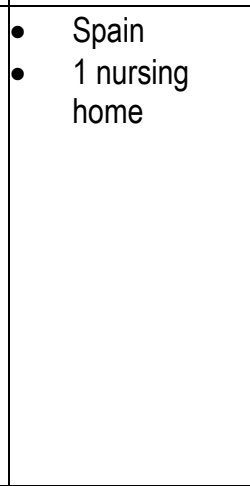 & $\begin{array}{ll}\text { - } & \text { QOL-AD } \\
\text { - } & \text { Participant psychotropic } \\
\text { - } & \text { medication dosage data } \\
& \text { Barthel Index }\end{array}$ & $\begin{array}{l}\text { Within AAT group comparison: } \\
\text { Q } \\
\text { Q did not reach statistical significance } \\
\text { - The IG and CG both improved on the Barthel Index, which measures performance in activities of } \\
\text { daily living }(p<.05) \\
\text { Between group comparison: } \\
\text { - No difference in psychotropic medication consumption was identified } \\
\text { - The increase in QOL in the CG was not different to the increase in the IG } \\
\text { - The IG improved more on the Barthel Index than the CG }(p<.05)\end{array}$ \\
\hline $\begin{array}{l}\text { (Travers et al., } \\
2013)^{35} \\
7 / 1353.8 \%\end{array}$ & $\begin{array}{l}\mathrm{N}=55 \\
12 \mathrm{M} \& 43 \mathrm{~F} \\
\mathrm{IG}=27 \\
\mathrm{CI}=28 \\
\mathrm{IG} \text { mean age } 84.9 \\
\mathrm{CG} \text { age }=85.1 \\
67 \text { residents were initially } \\
\text { recruited (7 IG and } 5 \mathrm{CG} \\
\text { participants withdrew) }\end{array}$ & $\begin{array}{ll}\text { - } & \text { Australia } \\
& 3 \text { residential } \\
& \text { aged care } \\
\text { facilities }\end{array}$ & $\begin{array}{ll}\text { - } & \text { QOL-AD } \\
\text { - } & \text { SF36 } \\
\text { - } & \text { GDS-SF } \\
\text { MOSES }\end{array}$ & $\begin{array}{l}\text { Between group comparison: } \\
\text { - In Facility } \mathrm{B} \text {, at } \mathrm{T} 2, \mathrm{QOL} \text { scores were greater in the IG compared to the Human-Therapist-Only } \\
\text { Control Intervention }(\mathrm{CI})(p<.05) \text {. In contrast, in Facility } \mathrm{C}, \mathrm{QOL} \text { scores were lower in the IG } \\
\text { compared to the } \mathrm{CI}(p<.05) \text {. An outbreak of gastroenteritis occurred in Facility } \mathrm{C} \text { during the final } \\
\text { week of the intervention that affected many participants and may have negatively influenced } \\
\text { their outcome scores. No differences in QOL were found in Facility A } \\
\text { - No difference between groups on the GDS-SF and SF36 } \\
\text { Relative to the } \mathrm{CI}, \mathrm{MOSES} \text { depression scores following intervention were moderately better in } \\
\text { IG participants with worse baseline scores, but not in those with low baseline scores }(p=0.03)\end{array}$ \\
\hline
\end{tabular}

(c) The Internet Journal of Allied Health Sciences and Practice, 2022 


\begin{tabular}{|c|c|c|c|c|}
\hline $\begin{array}{l}\text { Study author(s), } \\
\text { year, and critical } \\
\text { appraisal score }\end{array}$ & $\begin{array}{l}\text { Participants } \\
\text { Intervention group = IG } \\
\text { Control Group = CG }\end{array}$ & $\begin{array}{l}\text { Country and } \\
\text { setting of study }\end{array}$ & Outcome measures & Reported outcomes \\
\hline $\begin{array}{l}(\text { Friedmann et al., } \\
2014)^{36} \\
9 / 1369.2 \%\end{array}$ & $\begin{array}{l}\mathrm{N}=40 \\
11 \mathrm{M} \& 29 \mathrm{~F} \\
\mathrm{IG}=22 \\
\mathrm{Cl}=18 \\
\mathrm{IG} \text { mean age } 79.59 \\
\mathrm{CG} \text { mean age } 82.11 \\
\\
40 \text { participants were initially } \\
\text { recruited. } 2 \text { IG participants died } \\
\text { and } 1 \text { changed facilities }\end{array}$ & 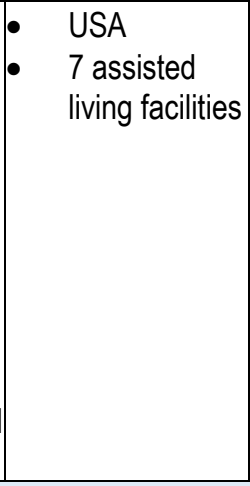 & $\begin{array}{ll}\text { - } & \text { Barthel Index } \\
\text { - } & \text { ActiGraph } 24 \mathrm{hr} \text { physical activity } \\
\text { measure } \\
\text { - } & \text { CSDD } \\
\text { - } & \text { CMS } \\
\text { - } & \text { Participant psychotropic } \\
& \text { medication dosage data }\end{array}$ & $\begin{array}{l}\text { Within AAT group comparison: } \\
\text { In stratified linear mixed models, CSDD scores decreased over time in the IG }(p<.05) \\
\text { Between group comparison: } \\
-\quad \text { No significant change in CMAl and Barthel Index scores for either group } \\
-\quad \text { No significant change in medication dosages for either group } \\
\text { - No significant change in physical activity in either group }\end{array}$ \\
\hline \multicolumn{5}{|c|}{ Quasi-Experimental studies } \\
\hline $\begin{array}{l}\left(\begin{array}{l}\text { Nordgren \& } \\
\text { Engström, 2014) }\end{array}\right. \\
7 / 977.7 \%\end{array}$ & $\begin{array}{l}N=20 \\
12 M \& 8 F \\
\text { Median age } 83 \\
9 \text { completed the program and } \\
\text { were included in the analysis }\end{array}$ & $\begin{array}{ll}\text { - } & \text { Sweden } \\
& 4 \text { nursing } \\
& \text { homes }\end{array}$ & - QUALID & $\begin{array}{l}\text { Within AAT group comparison: } \\
-\quad \text { QOL scores improved from T1 to T2 }(p<.05)\end{array}$ \\
\hline $\begin{array}{l}(\text { Thodberg et al., } \\
2016)^{13} \\
7 / 977.7 \%\end{array}$ & $\begin{array}{l}\mathrm{N}=100 \\
31 \mathrm{M} \& 69 \mathrm{~F} \\
\text { AAT group }=35 \\
\text { Robot group }=35 \\
\text { Toy cat group }=30 \\
\text { Median age } 85.5 \\
23 \text { withdrew during the } \\
\text { experimental period. } 1 \\
\text { participant is not accounted for } \\
\text { in the study }\end{array}$ & 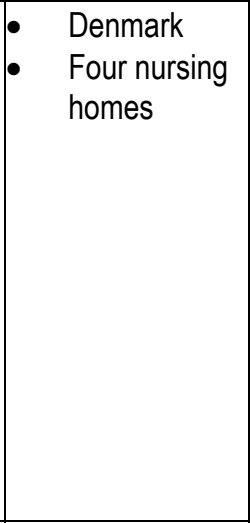 & $\begin{array}{ll}\text { - } & \text { MMSE } \\
\text { - } & \text { GBS } \\
\text { - } & \text { GDS } \\
\text { - } & \text { SMI } \\
& \text { Sleep data was measured } \\
\text { overnight on four occasions: } & \text { Week prior to AAT } \\
\text { Week } 3 \\
\text { Week } 6 \\
\text { Week after AAT }\end{array}$ & $\begin{array}{l}\text { Within group comparison: } \\
\text { - On average, across all groups, an improvement in GDS scores was recorded }(p<.05) \\
\text { - } \quad \text { On average, across all groups GBS and MMSE scores worsened }(p<.05) \\
\text { Between group comparison: } \\
\text { - } \quad \text { Sleep efficiency and sleep fragmentation did not change in any group } \\
\text { - } \quad \text { Visit type did not affect MMSE, GDS and or GBS scores }\end{array}$ \\
\hline $\begin{array}{l}\text { (Vrbanac et al., } \\
2013)^{38}\end{array}$ & $\begin{array}{l}N=21 \\
4 \mathrm{M} \& 17 \mathrm{~F}\end{array}$ & 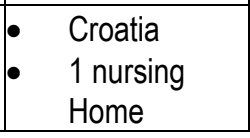 & $\begin{array}{l}\text { UCLA Loneliness Scale } \\
\text { A questionnaire designed } \\
\text { specifically for this study }\end{array}$ & $\begin{array}{l}\text { Within AAT group comparison: } \\
\text { - } \quad \text { UCLA scores improved from T1 to T2 }(p<.05) \\
\text { - } \quad 90 \% \text { of participants reported that taking care of an animal was important }\end{array}$ \\
\hline
\end{tabular}

(c) The Internet Journal of Allied Health Sciences and Practice, 2022 


\begin{tabular}{|c|c|c|c|c|}
\hline $\begin{array}{l}\text { Study author(s), } \\
\text { year, and critical } \\
\text { appraisal score }\end{array}$ & $\begin{array}{l}\text { Participants } \\
\text { Intervention group = IG } \\
\text { Control Group = CG }\end{array}$ & $\begin{array}{l}\text { Country and } \\
\text { setting of study }\end{array}$ & Outcome measures & Reported outcomes \\
\hline $6 / 966 \%$ & Mean age 80.5 & & $\begin{array}{l}\text { Observations and evaluation of } \\
\text { social interactions during AAT and } \\
\text { residents' behaviour towards the } \\
\text { animals }\end{array}$ & $\begin{array}{l}\text { - } 100 \% \text { of participants reported enjoying spending time with the dogs } \\
\text { - } \quad \begin{array}{l}96 \% \text { of participants reported that their mood improved due to spending time with the animal } \\
\text { By the end of the study, participants were arriving earlier than scheduled for AAT and would } \\
\text { engage each other in free conversation }\end{array}\end{array}$ \\
\hline $\begin{array}{l}\text { (Tournier et al., } \\
2017)^{39} \\
5 / 955 \%\end{array}$ & $\begin{array}{l}\mathrm{N}=11 \\
1 \mathrm{M} \& 10 \mathrm{~F} \\
\text { Mean age } 82.91\end{array}$ & $\begin{array}{ll}\text { - } & \text { France } \\
& 1 \text { nursing } \\
\text { Home }\end{array}$ & $\begin{array}{l}\text { - A systematic assessment of } \\
\text { behaviours during the first } 19 \text { AAT } \\
\text { sessions } \\
\text { NPI }\end{array}$ & $\begin{array}{l}\text { Within AAT group comparison: } \\
\text { - No significant change in total NPI scores. There was a significant decrease in caregiver ratings } \\
\text { of distress, symptoms of depression, aberrant motor activity, and disinhibition }(p<.05) \\
\text { - AAT had a significant positive impact on all behavioural categories }(p<.05)\end{array}$ \\
\hline $\begin{array}{l}\text { (Wesenberg et al., } \\
2019)^{40} \\
7 / 977.7 \%\end{array}$ & $\begin{array}{l}\mathrm{N}=19 \\
4 \mathrm{M} \& 13 \mathrm{~F} \\
\text { Mean age } 85.65 \\
\text { Participants acted as their own } \\
\text { controls } \\
19 \text { participants were initially } \\
\text { recruited. } 1 \text { died and } 1 \\
\text { withdrew }\end{array}$ & $\begin{array}{ll}- & \text { Germany } \\
\text { - } & 2 \text { nursing } \\
\text { homes }\end{array}$ & $\begin{array}{l}\text { Outcomes examined were } \\
\text { - } \quad \text { social interaction } \\
\text { emotional expression } \\
\text { behavioural and psychological } \\
\text { Outcomes were evaluated using video } \\
\text { recordings } \\
\text { Emotional expression coding was } \\
\text { based on the Facial Action Coding } \\
\text { System and the Observed Emotion } \\
\text { Rating Scale (modified) }\end{array}$ & $\begin{array}{l}\text { Within group comparison: } \\
\text { - Longer and more frequent periods of positive emotions and social interaction were observed } \\
\text { with AAT compared to the } \mathrm{Cl}(p<.05) \\
\text { - AAT resulted in more and longer upper body movements }(p<.05) \text { compared to the } \mathrm{Cl} \text {. } \\
\text { - Significant differences in } \mathrm{T} 1 \text { to T3 changes between AAT and } \mathrm{Cl} \text {, in length of pleasure in } \\
\text { seconds } \\
\text { Physical contact between participants and dogs was longer in AAT than the } \mathrm{Cl} \text { at T1, T2 and T3 } \\
(P<0.05) . \text { No significant difference between time points was observed }\end{array}$ \\
\hline $\begin{array}{l}\text { (Nordgren \& } \\
\text { Engström, 2014) } 41 \\
8 / 988 \%\end{array}$ & \begin{tabular}{|l|}
$N=33$ \\
$11 \mathrm{M} \& 22 \mathrm{~F}$ \\
$\mathrm{IG}=20$ \\
$\mathrm{CG}=13$ \\
$\mathrm{IG}$ mean age 81 \\
$\mathrm{CG}$ mean age 83 \\
33 participants initially \\
recruited. 7 IG participants died \\
and 2 moved out, 2 CG \\
participants died and 3 moved \\
out
\end{tabular} & $\begin{array}{ll}\text { - } & \text { Sweden } \\
8 \text { nursing } \\
\text { homes }\end{array}$ & CMAI & $\begin{array}{l}\text { Within AAT group comparison: } \\
\text { - The mean verbal agitation score on the CMAI worsened from T1 to T3 in the IG }(p<0.05) \text {. No } \\
\text { other CMAI scores were significant } \\
\text { - No significant changes in mean MDDAS and subscale scores } \\
\text { - No significant change in MMSE scores }\end{array}$ \\
\hline
\end{tabular}




\begin{tabular}{|c|c|c|c|c|}
\hline $\begin{array}{c}\text { Study author(s), } \\
\text { year, and critical } \\
\text { appraisal score }\end{array}$ & $\begin{array}{c}\text { Participants } \\
\text { Intervention group = IG } \\
\text { Control Group = CG }\end{array}$ & $\begin{array}{l}\text { Country and } \\
\text { setting of study }\end{array}$ & Outcome measures & Reported outcomes \\
\hline $\begin{array}{l}(\text { Moretti et al., } \\
2011)^{42} \\
8 / 988 \%\end{array}$ & $\begin{array}{l}N=21 \\
1 \mathrm{M} \& 20 \mathrm{~F} \\
\mathrm{IG}=10 \\
\mathrm{CG}=11 \\
\text { Mean age } 84.7\end{array}$ & 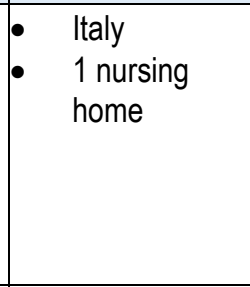 & $\begin{array}{ll}\text { - } & \text { MMSE } \\
\text { - } & \text { GDS } \\
& \text { A self-perceived QOL } \\
& \text { questionnaire }\end{array}$ & $\begin{array}{l}\text { Within group comparison: } \\
\text { - } \quad \text { Mean MMSE scores increased from T1 to T2 in the IG }(p<0.05) \\
\text { - } \quad \text { GDS scores improved for both groups from T1 to T2 }(p<.05) \\
\text { Between group comparison: } \\
\text { - } \quad \text { GDS scores improved more in the IG compared to the CG }(p<0.05) \\
\text { - } \quad \text { IG and } 2 \text { CG participants reported improvement in perceived QOL }\end{array}$ \\
\hline $\begin{array}{l}(\text { Berry et al., } \\
2012)^{43} \\
9 / 9100 \%\end{array}$ & $\begin{array}{l}\mathrm{N}=19 \\
6 \mathrm{M} \& 13 \mathrm{~F} \\
\text { Mean age } 85\end{array}$ & 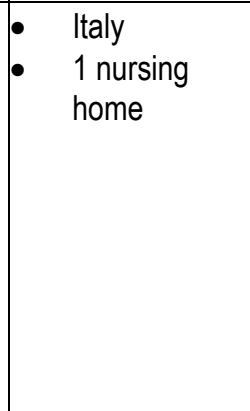 & $\begin{array}{l}\text { - Behavioural assessment of video } \\
\text { recordings (scored using The } \\
\text { Observer 3.0, Noldus) } \\
\text { - Saliva cortisol levels } \\
\text { GDS }\end{array}$ & $\begin{array}{l}\text { Within AAT group comparison: } \\
\text { Participants were observed smiling more while spontaneously interacting during both contact } \\
\text { and play activities during mediated interactions with dogs compared to human interaction }(p< \\
\text {.05) } \\
\text { No statistically significant difference was found in cortisol levels collected from T1 to T2 for the } \\
\text { IG or the CG } \\
\text { SS-CG participants showed a circadian rhythm-based decrease in salivary cortisol }(p<.05) \text {, this } \\
\text { decrease was not observed in the SS group } \\
\text { All AAT physical therapy sessions (PS) and (SS) with dog interactions were characterised by } \\
\text { lower depressive states than the controls }(p<.05)\end{array}$ \\
\hline $\begin{array}{l}(\text { Nordgren \& } \\
\text { Engstrom, 2012) })^{44} \\
6 / 966.6 \%\end{array}$ & $\begin{array}{l}N=1 \\
1 \mathrm{~F} \\
\text { Aged } 84\end{array}$ & 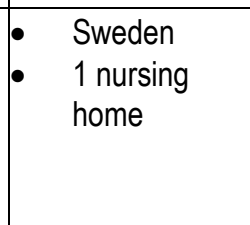 & $\begin{array}{ll}\text { - } & \text { MMSE } \\
\text { - } & \text { CMAI } \\
\text { - } & \text { MDDAS } \\
\text { - } & \text { ADL taxonomy } \\
\text { - } & \text { QUALID }\end{array}$ & $\begin{array}{l}\text { Within AAT comparison: } \\
\text { - Some differences in the participant's ability to move and walk, and some effects on cognitive } \\
\text { state were identified, however they were not significant }\end{array}$ \\
\hline $\begin{array}{l}(\text { Swall et al., } \\
2014)^{45} \\
6 / 966.6 \%\end{array}$ & $\begin{array}{l}\mathrm{N}=5 \\
1 \mathrm{M} \& 4 \mathrm{~F} \\
\text { Aged } 89-95\end{array}$ & $\begin{array}{l}\text { - } \quad \text { Sweden } \\
1 \text { nursing } \\
\text { home }\end{array}$ & $\begin{array}{l}\text { - ActiGraph } 24 \mathrm{hr} \text { daytime physical } \\
\text { activity, sleep onset and night- } \\
\text { time activity measure }\end{array}$ & $\begin{array}{l}\text { Within AAT group comparison: } \\
\text { - } \quad \text { No clear pattern of AAT effect was show on the daytime activity and sleep of individuals }\end{array}$ \\
\hline $\begin{array}{l}\text { (Kårefjärd \& } \\
\text { Nordgren, 2019)46 } \\
7 / 977.7 \%\end{array}$ & $\begin{array}{l}N=59 \\
25 \mathrm{M} \& 34 \mathrm{~F} \\
\text { Mean age } 81\end{array}$ & \begin{tabular}{|l} 
- $\quad$ Sweden \\
3 nursing \\
homes
\end{tabular} & - QUALID & $\begin{array}{l}\text { Within AAT group comparison: } \\
\text { - QUALID scores improved from T1 to T2 }(p<0.05) \text {, and worsened from T2 to T3 }(p<0.05)\end{array}$ \\
\hline
\end{tabular}

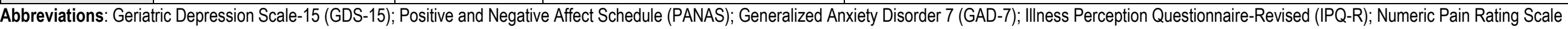

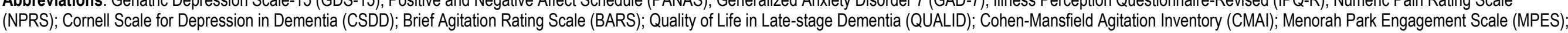

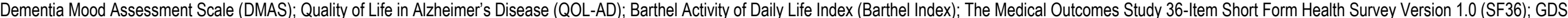

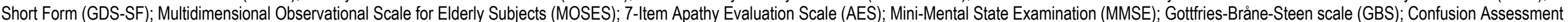
Method (CAM); Body Mass Index (BMI); The Neuropsychiatric Inventory (NPI); Multi-Dimensional Dementia Assessment Scale (MDDAS); T1 = Pre intervention; T2 = Post Intervention; T3 = Follow up 
Table 4: AAT Intervention Details

\begin{tabular}{|c|c|}
\hline $\begin{array}{c}\text { Study } \\
\text { Authors }\end{array}$ & Details of Animal Assisted Therapy \\
\hline \multicolumn{2}{|c|}{ Randomised Controlled Trials } \\
\hline$\left(\right.$ Ambrosi et al., 2019) ${ }^{33}$ & 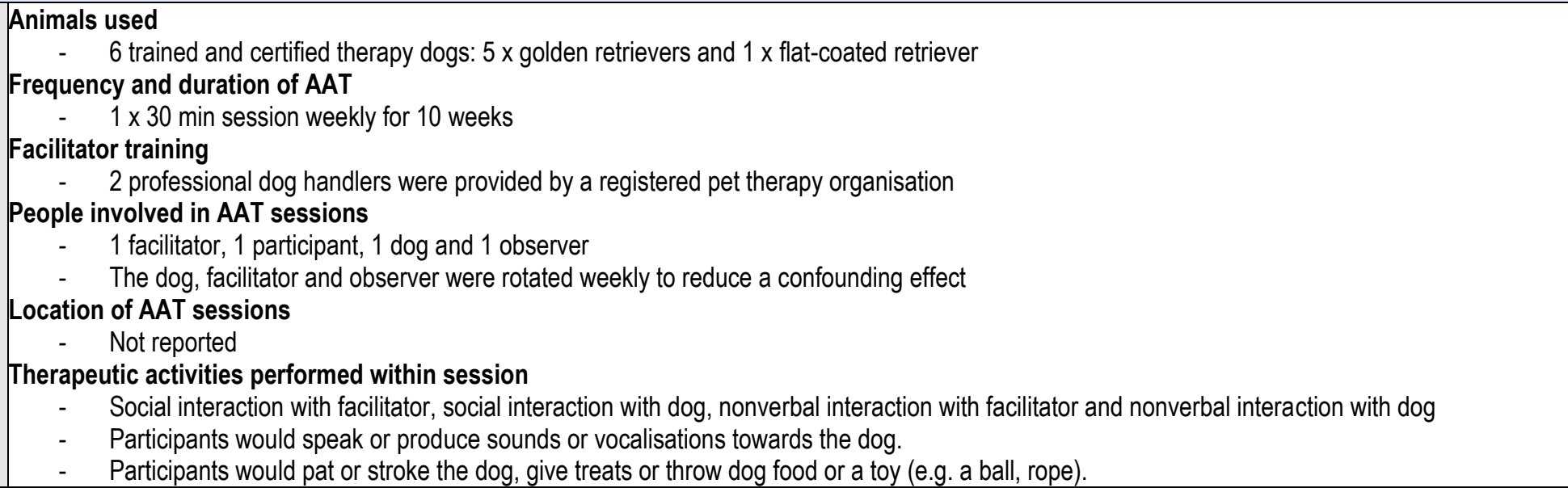 \\
\hline
\end{tabular}

(c) The Internet Journal of Allied Health Sciences and Practice, 2022 


\begin{tabular}{|c|c|}
\hline$($ Pope et al., 2016) & 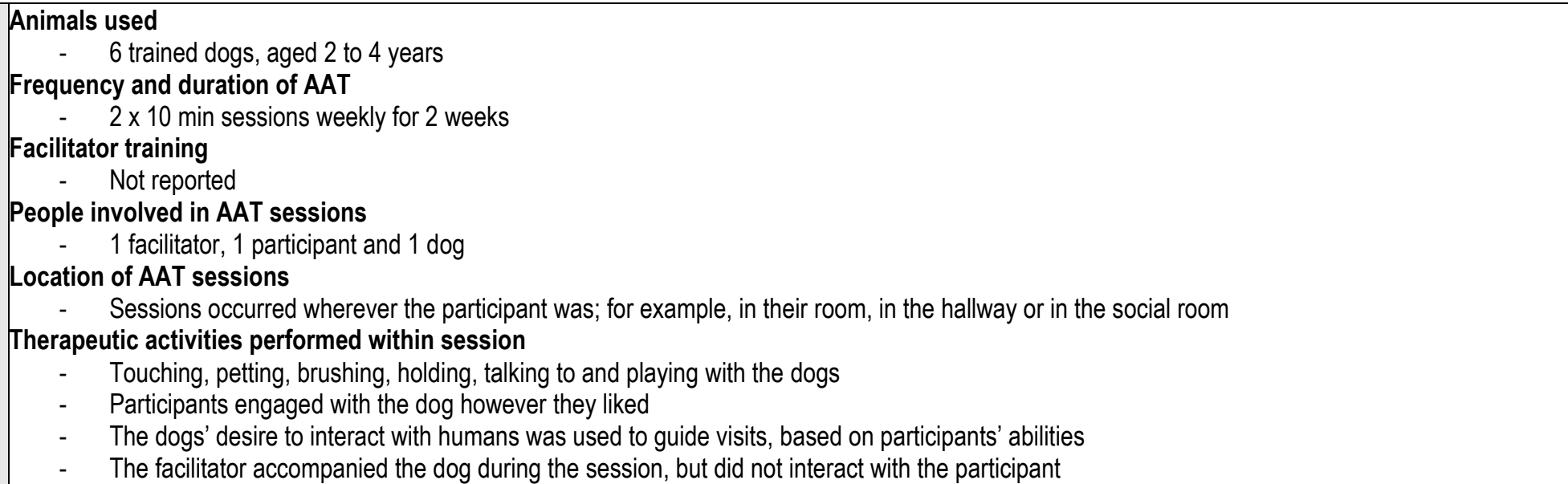 \\
\hline$\left(\right.$ (Majic et al., 2013) ${ }^{17}$ & $\begin{array}{l}\text { Animals used } \\
\text { Frequency and duration of AAT } \\
\text { - } 1 \text { x } 45 \text { min session weekly for } 10 \text { weeks } \\
\text { Facilitator training } \\
-\quad \text { Not reported } \\
\text { People involved in AAT sessions } \\
-\quad 1 \text { facilitator, } 1 \text { participant and } 1 \text { dog } \\
\text { Location of AAT sessions } \\
\text { - } \quad \text { Not reported } \\
\text { Therapeutic activities performed within session } \\
\text { - } \quad \text { The facilitator introduced the dog each session and informed participants of when it would visit } \\
\text { - } \quad \text { Sessions began with verbal interaction between the facilitator, the dog and the participant } \\
\text { - } \quad \text { Participants would pat or stroke the dog. Interactions such as throwing and retrieving balls was possible with }<10 \% \text { of participants } \\
\text { - } \quad \text { Final } 15 \text { mins of sessions were for free interaction between dogs and participants } \\
\text { - } \quad \text { The facilitator only engaged if the participant asked a question }\end{array}$ \\
\hline$($ Briones et al., 2019)34 & 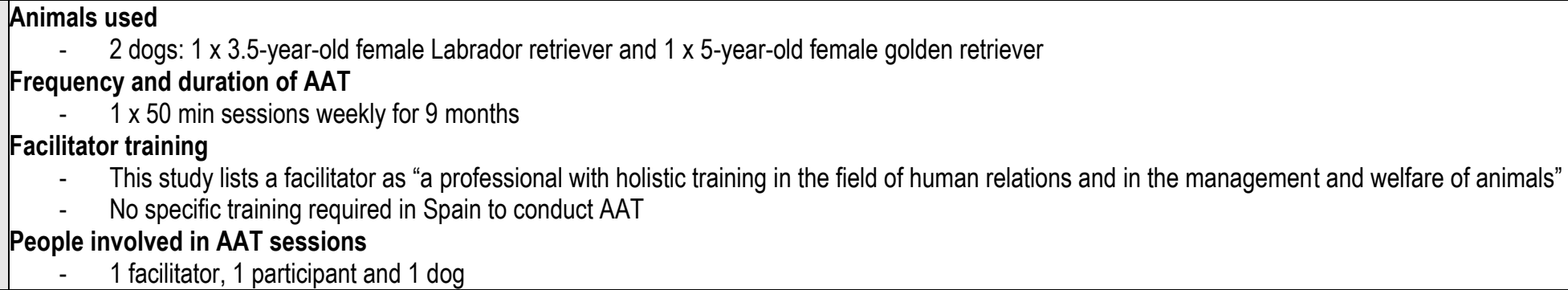 \\
\hline
\end{tabular}

(c) The Internet Journal of Allied Health Sciences and Practice, 2022 


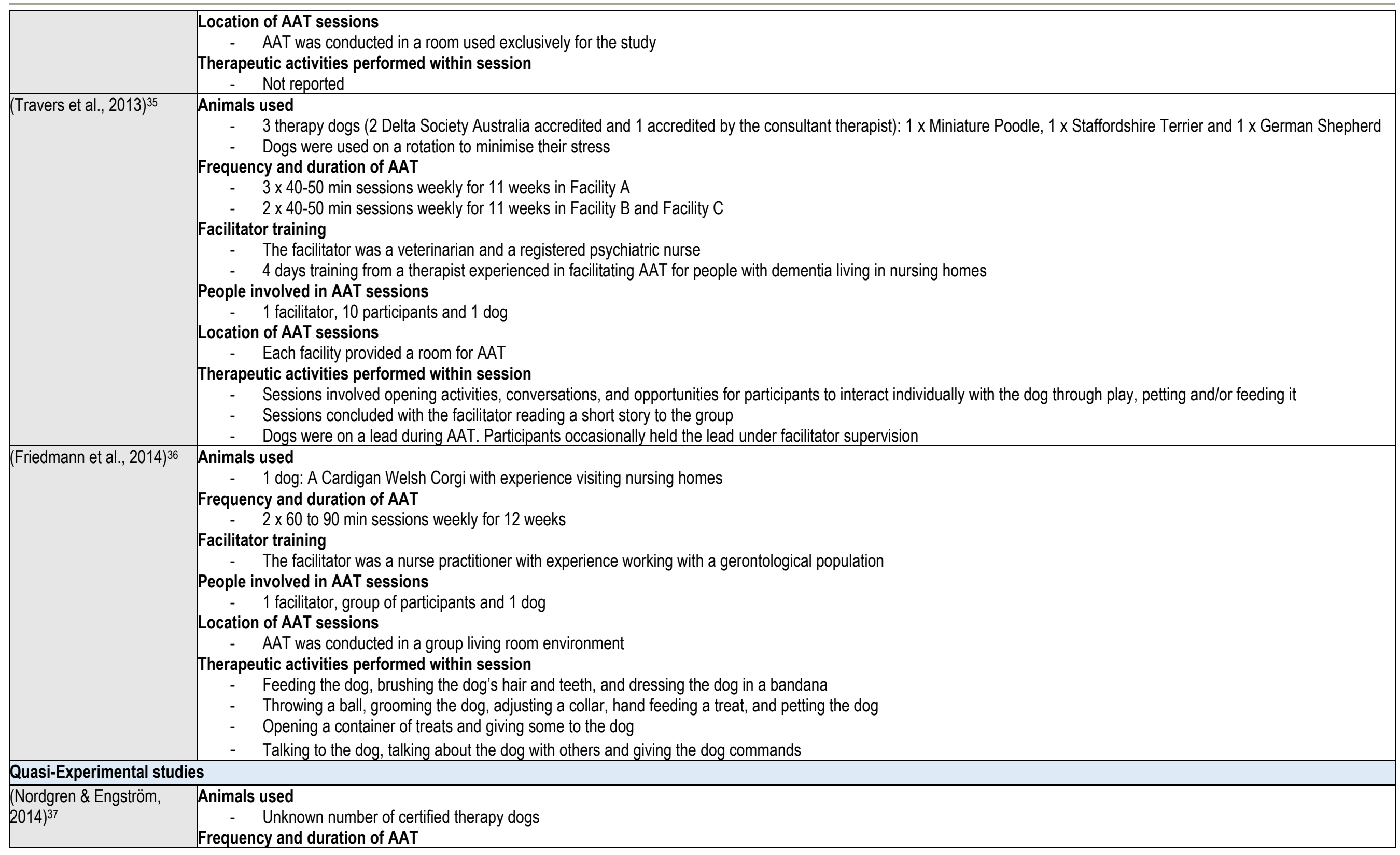

(c) The Internet Journal of Allied Health Sciences and Practice, 2022 


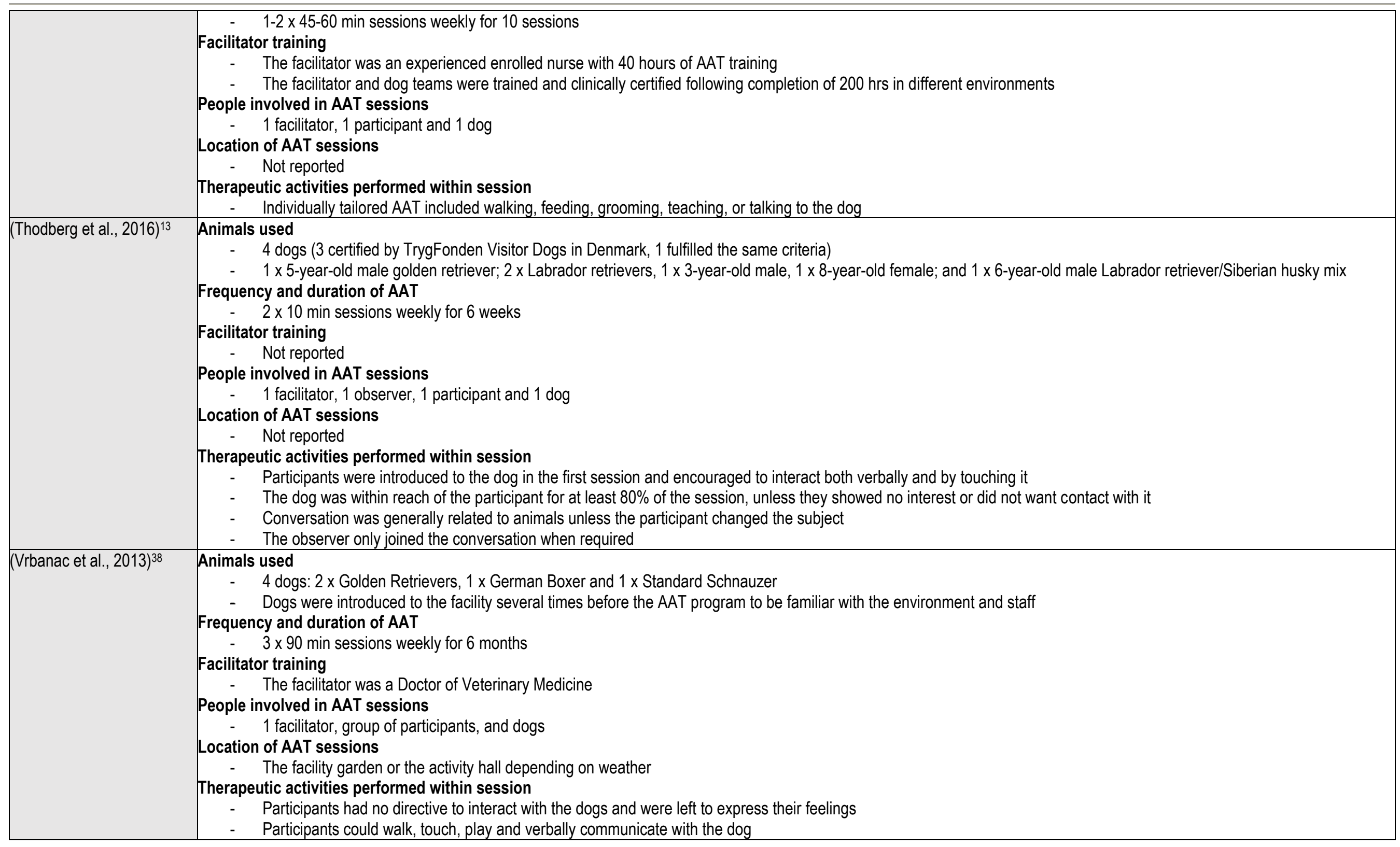




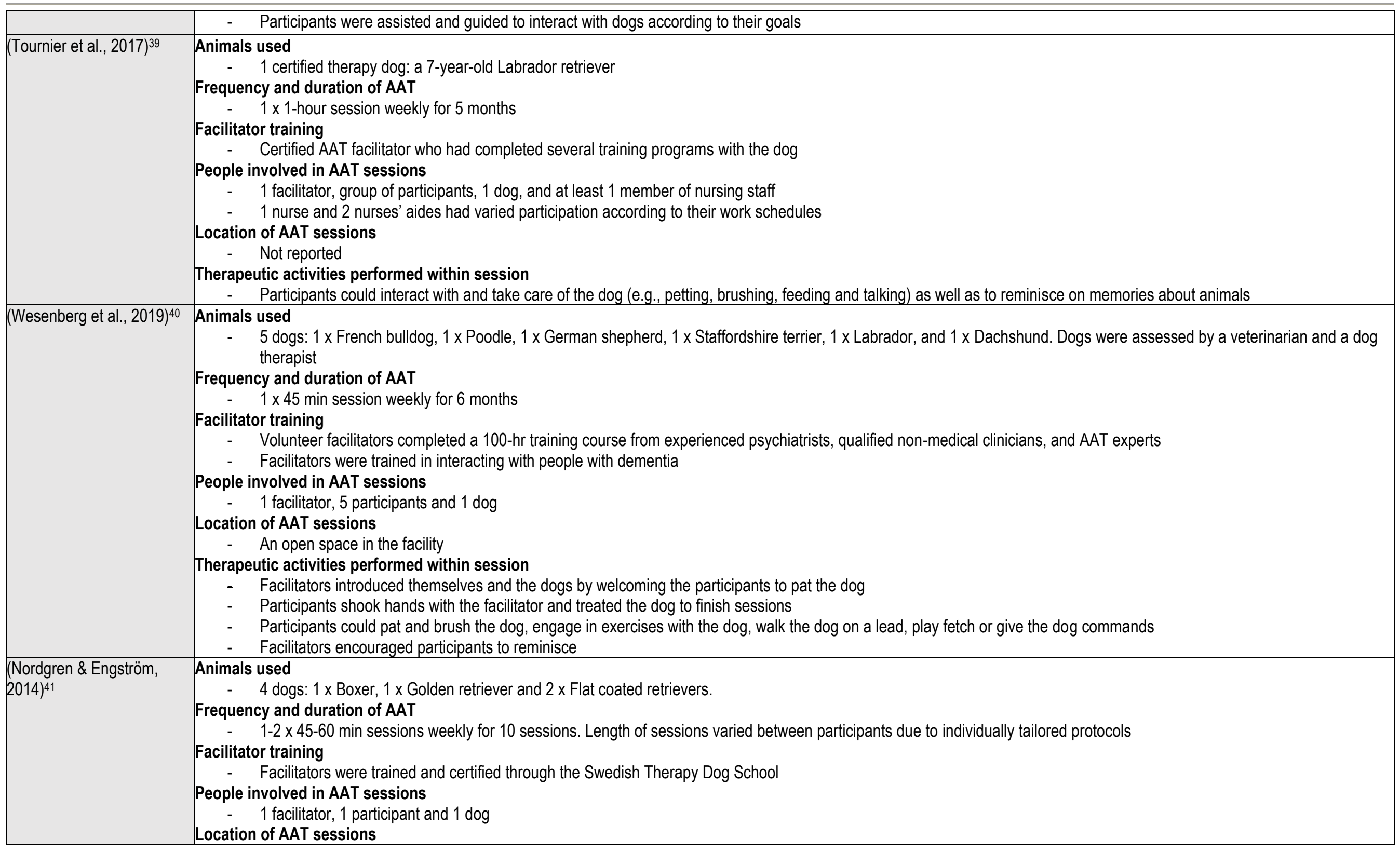

(c) The Internet Journal of Allied Health Sciences and Practice, 2022 


\begin{tabular}{|c|c|}
\hline & $\begin{array}{l}\text { - } \quad \text { AAT was conducted in participant apartments } \\
\text { Therapeutic activities performed within session } \\
\text { - } \quad \text { Activities included: patting and talking to the dog, brushing it, walking or playing with it, feeding it treats, reminiscing about past pets, or talking to the facilitator. The facilitator } \\
\text { always controlled the dog } \\
\text { - } \quad \text { The facilitator began the session by introducing the dog to participants } \\
\text { - } \quad \text { The facilitator encouraged communication and affirmed the participant's emotions and feelings }\end{array}$ \\
\hline$($ Moretti et al., 2011) & $\begin{array}{l}\text { Animals used } \\
-\quad 4 \text { trained dogs: } 3 \text { x Golden Retrievers and } 1 \text { x Pinscher } \\
\text { Frequency and duration of AAT } \\
-\quad 1 \times 90 \text { min sessions weekly for } 6 \text { weeks } \\
\text { Facilitator training } \\
-\quad \text { Not reported } \\
\text { People involved in AAT sessions } \\
-\quad 1 \text { facilitator, group of participants, and dogs } \\
\text { Location of AAT sessions } \\
-\quad \text { Inside and outside the nursing home } \\
\text { Therapeutic activities performed within session } \\
-\quad \text { Participants walked, patted, talked to and played with the dogs, under facilitator supervision }\end{array}$ \\
\hline$\left(\right.$ Berry et al., 2012) ${ }^{43}$ & 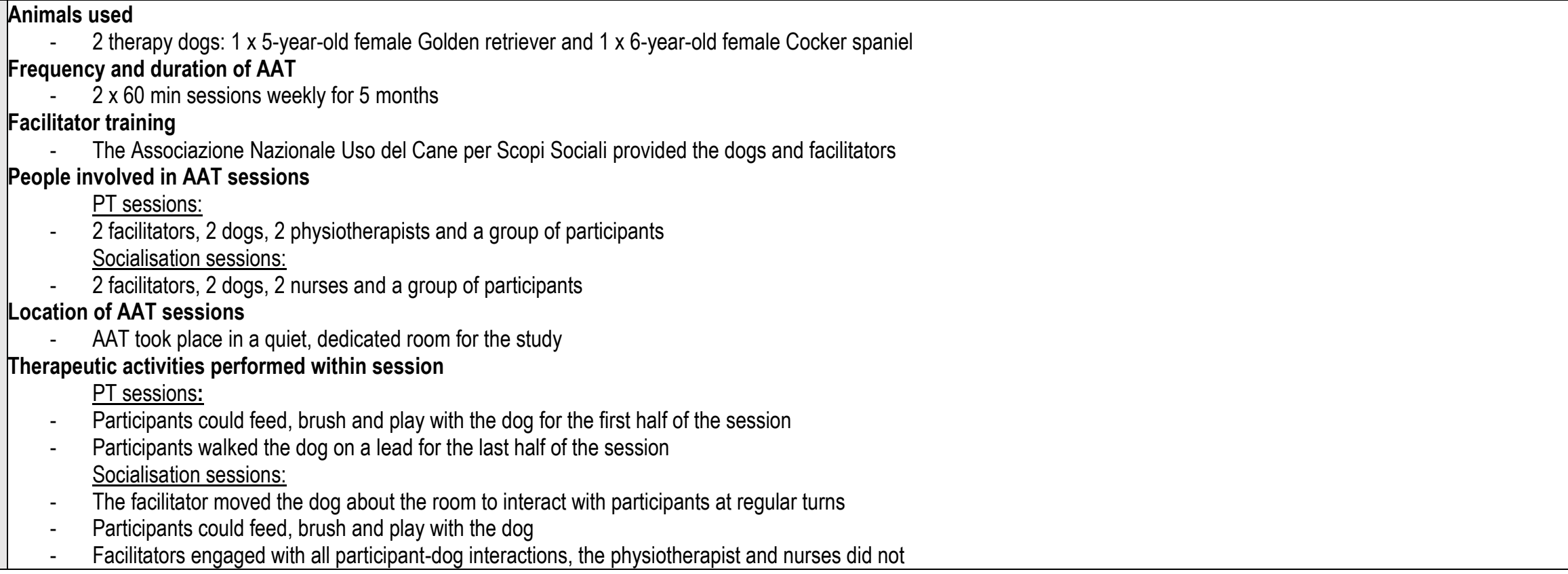 \\
\hline
\end{tabular}




\begin{tabular}{|c|c|}
\hline $\begin{array}{l}\text { (Nordgren \& Engstrom, } \\
2012)^{44}\end{array}$ & 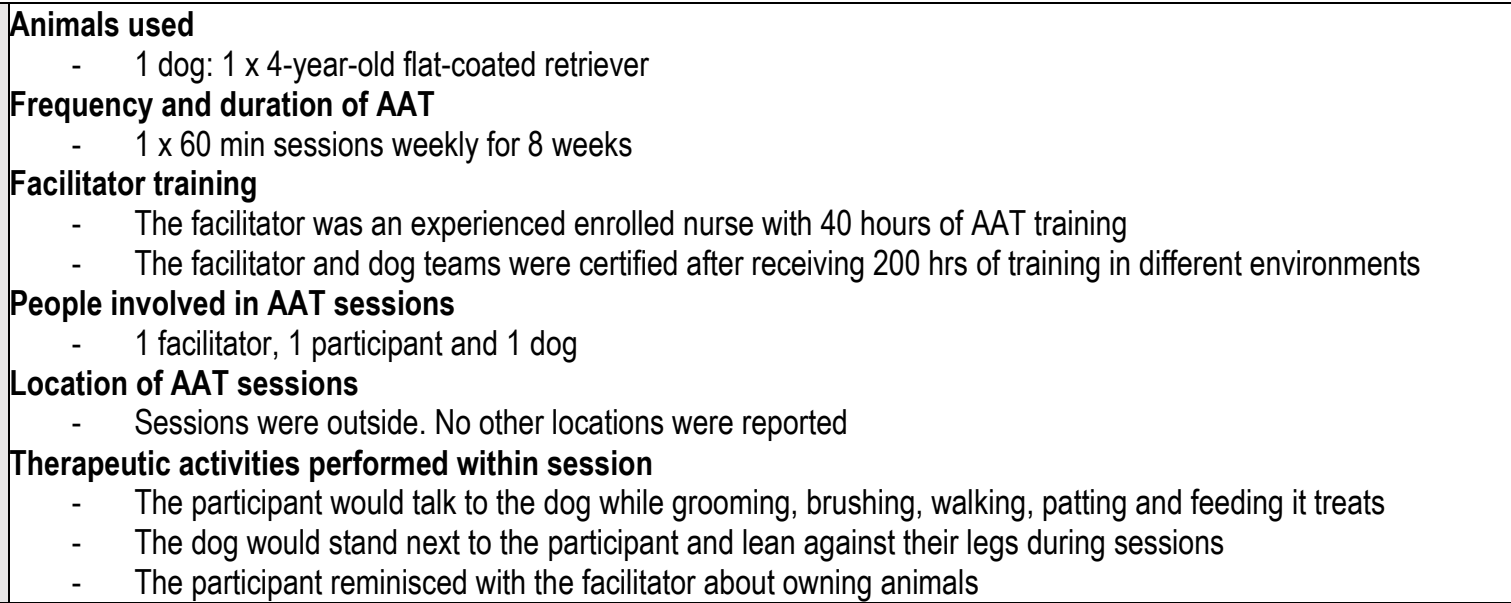 \\
\hline$($ Swall et al., 2014)45 & 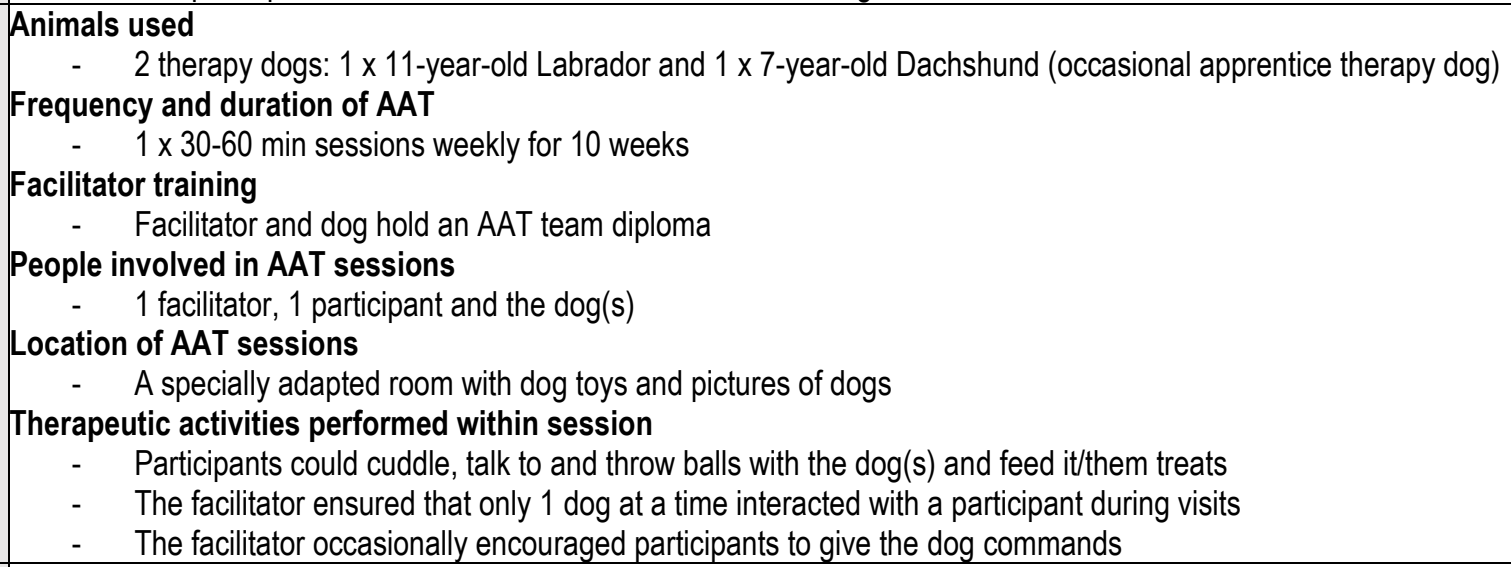 \\
\hline $\begin{array}{l}\text { (Kårefjärd \& Nordgren, } \\
2019)^{46}\end{array}$ & $\begin{array}{l}\text { Animals used } \\
-\quad 2 \text { certified therapy dogs: } 2 \text { x flat-coated retrievers } \\
\text { Frequency and duration of AAT } \\
-\quad 2 \text { x } 20-40 \text { min sessions weekly for } 10 \text { sessions } \\
\text { Facilitator training } \\
-\quad \text { In Sweden, facilitator and dog teams, are trained and certified in accordance with a national standard } \\
\text { People involved in AAT sessions } \\
-\quad 1 \text { facilitator, } 1 \text { participant and } 1 \text { dog } \\
\text { Location of AAT sessions } \\
-\quad \text { Indoors and/or outdoors depending on activities } \\
\text { Therapeutic activities performed within session }\end{array}$ \\
\hline
\end{tabular}

(c) The Internet Journal of Allied Health Sciences and Practice, 2022 
The participant could pat the dog, play with it, groom it, feed it treats, hold its lead while walking inside and outside, and talk to it

Table 5: Outcomes Assessed in Each Study and Key Findings

\begin{tabular}{|c|c|c|c|c|c|c|c|c|c|c|c|c|c|c|}
\hline \multirow[t]{2}{*}{ Study Authors } & \multicolumn{14}{|c|}{ Outcomes measured and key findings } \\
\hline & Depression & $\begin{array}{l}\text { Anxietyl } \\
\text { Stress }\end{array}$ & Agitation & Quality of Life & $\begin{array}{l}\text { Engagement, } \\
\text { Apathy and } \\
\text { Affect }\end{array}$ & $\begin{array}{l}\text { Activities of } \\
\text { Daily Living } \\
\text { function }\end{array}$ & Sleep & $\begin{array}{c}\text { Medication } \\
\text { dosage }\end{array}$ & $\begin{array}{c}\text { Physical } \\
\text { activity }\end{array}$ & $\begin{array}{c}\text { Health Status/ } \\
\text { Illness }\end{array}$ & Pain & $\begin{array}{c}\text { Socio- } \\
\text { emotional } \\
\text { Behaviours }\end{array}$ & $\begin{array}{c}\text { Symptoms of } \\
\text { Dementia }\end{array}$ & Loneliness \\
\hline \multicolumn{15}{|c|}{ Randomised Controlled Trials } \\
\hline (Ambrosi et al., & $\checkmark$ & - & & & - & & & & & - & & & & \\
\hline $\begin{array}{l}\text { (Olsen et al., } \\
2016)^{22}\end{array}$ & $\checkmark$ Severe dementia & & - & $\checkmark$ Severe dementia & & & & & & & & & & \\
\hline$\left(\right.$ Pope et al., 2016) ${ }^{16}$ & & & \begin{tabular}{|l|} 
\\
$\checkmark$ \\
overall \\
screaming a aggression
\end{tabular} & & - & & & & & & & $\checkmark$ & & \\
\hline$(\text { Majic et al., 2013) })^{17}$ & $\checkmark$ & & $\checkmark$ & & & & & & & & & & & \\
\hline \begin{tabular}{l|} 
(Briones et al., \\
$2019)^{34}$
\end{tabular} & & & & - & & $\checkmark$ & & - & & & & & & \\
\hline $\begin{array}{l}\text { (Travers et al., } \\
2013)^{35}\end{array}$ & \begin{tabular}{|l|}
$\checkmark$ for worse baseline \\
scores
\end{tabular} & & & \begin{tabular}{|l} 
Facility A \\
$\checkmark$ Facility B \\
X Facility C - gastro
\end{tabular} & & & & & & - & & & & \\
\hline \begin{tabular}{l|} 
Friedmann et al., \\
$2014)^{36}$
\end{tabular} & $\checkmark$ & & - & & - & - & & - & - & & & & & \\
\hline \multicolumn{15}{|c|}{ Quasi-Experimental studies } \\
\hline \begin{tabular}{l|} 
(Nordgren \& \\
Engström, 2014)
\end{tabular} & & & & $\checkmark$ & & & & & & & & & & \\
\hline $\begin{array}{l}\text { (Thodberg et al., } \\
\text { 2016) }\end{array}$ & $\checkmark$ & & & & & & & & & - & & & $X$ & \\
\hline $\begin{array}{l}\text { (Vrbanac et al., } \\
\text { 2013)38 }\end{array}$ & & & & & & & & & & & & & & $\checkmark$ \\
\hline $\begin{array}{l}\text { (Tournier et al., } \\
2017)^{39}\end{array}$ & $\checkmark$ & & & & & & & & & & & $\checkmark$ & \begin{tabular}{|l|} 
Overall \\
$\checkmark$ caregiver distress \\
ratings, dep, aberrant \\
motor activity, and \\
disishnibition \\
\end{tabular} & \\
\hline $\begin{array}{l}\text { (Wesenberg et al., } \\
2019)^{40}\end{array}$ & & & & & & & & & & & & $\checkmark$ & & \\
\hline $\begin{array}{l}\text { (Nordgren \& } \\
\text { Engström, 2014) }\end{array}$ & & & \begin{tabular}{|l|}
$\mathbf{X}$ verbal agitation \\
\end{tabular} & & & & & & & & & & - & \\
\hline
\end{tabular}




\begin{tabular}{|c|c|c|c|c|c|c|c|c|c|c|c|c|c|c|}
\hline \multirow[t]{2}{*}{ Study Authors } & \multicolumn{14}{|c|}{ Outcomes measured and key findings } \\
\hline & Depression & $\begin{array}{l}\text { Anxiety/ } \\
\text { Stress }\end{array}$ & Agitation & Quality of Life & $\begin{array}{c}\text { Engagement, } \\
\text { Apathy and } \\
\text { Affect }\end{array}$ & $\begin{array}{l}\text { Activities of } \\
\text { Daily Living } \\
\text { function }\end{array}$ & Sleep & $\begin{array}{c}\text { Medication } \\
\text { dosage }\end{array}$ & $\begin{array}{c}\text { Physical } \\
\text { activity }\end{array}$ & $\begin{array}{c}\text { Health StatusI } \\
\text { IIIness }\end{array}$ & Pain & $\begin{array}{c}\text { Socio- } \\
\text { emotional } \\
\text { Behaviours }\end{array}$ & $\begin{array}{c}\text { Symptoms of } \\
\text { Dementia }\end{array}$ & Loneliness \\
\hline $\begin{array}{l}\text { (Moretti et al., } \\
2011)^{42}\end{array}$ & $\checkmark$ & & & - & & & & & & & & & $\checkmark$ & \\
\hline$(\text { Berry et al., 2012) })^{43}$ & $\checkmark$ & - & & & & & & & & & & $\checkmark$ & & \\
\hline \begin{tabular}{|l|} 
Nordgren \& \\
Engstrom, 2012)
\end{tabular} & & & - & - & & - & & & & & & & - & \\
\hline$($ Swall et al., 2014) & & & & & & & - & & - & & & & & \\
\hline $\begin{array}{l}\text { (Kårefjärd \& } \\
\text { Nordgren, 2019)46 }\end{array}$ & & & & $\checkmark$ & & & & & & & & & & \\
\hline
\end{tabular}

Key: $\checkmark=$ Significant Improvement (overtime or between groups), $\mathbf{X}=$ Significant Worsening, $-=$ No Significant Change/Difference, Blank $=$ Not Assessed. 


\section{Narrative Synthesis}

The narrative synthesis reported below, sought to identify key characteristics of effective AAT interventions, with a focus on answering the previously identified research questions regarding the optimal: frequency and duration of AAT; animals used; facilitator training; animal training/certification; environment/setting; and therapeutic activities included in AAT sessions. Each of the following sections addresses one of the identified research questions.

\section{What Intervention Frequencies and Durations Support Effective AAT with Older Adults in Aged Care Facilities?}

Nine of the 18 included studies assessed the effects of AAT on depression. All nine studies found that AAT was effective at reducing depression or symptoms of depression. The effect of AAT on depression or depressive symptoms did not appear to be impacted by the frequency or duration of AAT sessions, or length of AAT intervention period, as presented in Table 4. For example, one study conducted one 30-minute session weekly for 10 weeks. ${ }^{33}$ In contrast, another study conducted two 30minute sessions weekly for 12 weeks. ${ }^{22}$ Both studies showed improvements in participant depression scores despite differences in session frequency and length of intervention period. Further, the study that conducted the shortest AAT sessions included two 10-minute sessions a week for six weeks whereas the study that conducted the longest AAT sessions involved one 90-minute session per week for six weeks. ${ }^{13,42}$ Both studies reported significant improvements in the depression scores of their participants. As reported in Table 4, the intervention period of included studies ranged from six weeks to five months, with all studies demonstrating that AAT was effective at reducing depression or depressive symptoms. It should also be noted that Olsen et al found the reduction in depression was more evident in participants with severe dementia, and Travers et al found depression reduced more in participants with worse baseline scores. ${ }^{22,35}$

Seven of the 18 included studies assessed the impact of AAT on QOL, as shown in Table 3. In studies assessing QOL, the duration and intervention period length did not appear to be related to the effectiveness of the AAT. In contrast, the frequency of sessions did appear to impact QOL outcomes. The frequency of AAT sessions ranged from one to three times a week. Facility A in the study by Travers et al was the only instance of AAT sessions occurring three times a week..$^{35}$ These more frequent sessions were not associated with improved QOL and staff at the facility reported that this time commitment was too great. Facility B and C in the same study implemented two AAT sessions per week. All other studies included in this review conducted AAT either once or twice a week. Among the studies that found improvements in QOL, two conducted AAT sessions twice a week and the other conducted sessions 1-2 times per week. No studies that conducted AAT only once a week found any improvements in QOL.

AAT appeared to be effective at improving participant outcomes in the four studies that measured participant socioemotional behaviours (Table 5). As shown in Table 4, studies measuring this outcome varied in frequency, duration and intervention period length, with AAT occurring 1-2 times per week, ranging between 10 to 60 minutes in duration, and with intervention period length ranging from two weeks to six months. As presented in Table 5 , the effect of AAT on participant socioemotional behaviours did not appear to be impacted by the frequency and duration of AAT sessions, or length of AAT intervention period. Six of the 18 included studies assessed the effect of AAT on agitation, specifically. As shown in Tables 3 and 5, the effectiveness of AAT in reducing levels of agitation varied. Similarly, as reported in Table 4, in studies that measured agitation the frequency, duration and intervention period length of AAT did not appear to impact the likelihood of AAT reducing levels of agitation.

\section{What Types of Animals are Effective to use in AAT with Older Adults in Aged Care Facilities?}

As presented in Table 4, dogs were the only animal used in the studies included in this review. Thirteen of the studies reviewed used dogs with some form of training and/or certification to deliver AAT, while the remaining five studies did not provide details of dog training. Of the 13 studies reporting use of trained/certified therapy dogs, $12(92.3 \%)$ demonstrated improvements among participants who received AAT in levels of depression, agitation, QOL, activities of daily living (ADLs) function, socioemotional behaviours, or symptoms of dementia. Two of these 13 studies (15.3\%) showed some deterioration in outcomes. One study found an increase in symptoms of dementia. ${ }^{13}$ Another found a deterioration in QOL. ${ }^{35}$ In contrast, only three of the five $(60 \%)$ studies that did not report specific training or certification of dogs used in AAT demonstrated improvements in levels of depression, ADL function, or loneliness with AAT. One of these five studies reported greater levels of agitation. ${ }^{41}$ It appears that the introduction of dogs to older adults in aged care facilities through AAT typically has positive impacts on mental health of the older adults, regardless of how the AAT is applied.

\section{What Type of Training Supports AAT Facilitators to Implement Effective AAT with Older Adults in Aged Care Facilities?}

All facilitator training types were associated with improvements in participant outcomes. Four studies did not report details of facilitator training. Of the 14 studies that did provide training information, two studies reported facilitators being provided training by an AAT organisation (without specifying training details), 10 studies reported some form of training in AAT, one study reported nursing training only, one study reported veterinary training only, and three studies reported a combination of the types of training listed previously. Of the 10 studies reporting use of AAT trained facilitators, seven (70\%) demonstrated 
improvements in depression, QOL, ADL function, socioemotional behaviours, or symptoms of dementia. One of the studies reporting AAT training found evidence of deterioration in QOL. ${ }^{35}$ Another study found an increase in levels of agitation. ${ }^{41}$ Both of the two studies reporting use of AAT organisation facilitators demonstrated improvements in depression and socioemotional behaviours. The study reporting use of nursing training only showed improvements in depression. The study reporting use of solely veterinary training demonstrated a reduction in loneliness. Two of the three studies reporting combinations of training types demonstrated improvements in depression and QOL. One of the three studies that reported combined training types reported a deterioration in QOL. ${ }^{35} \mathrm{AAT}$ organisation provided facilitators, veterinary training, and nursing training were all associated with improvement in at least one outcome. AAT training was shown to be the next training type associated with improved outcomes. A combined approach to facilitator training was least likely to show consistent improvements. It should be noted, however, that only one study reported veterinary training and one study reported nursing training, and these were both associated with improvement in only one positive outcome.

What Environments/Settings Support the Implementation of Effective AAT with Older Adults in Aged Care Facilities? As shown in Table 3, all studies were conducted in nursing homes, assisted living facilities or residential aged care facilities. Six studies did not report any detail regarding the location of AAT sessions. Table 4 shows that eight studies were set in an inside environment, three studies were set both inside and outside, and one case study was set outside. Six of the eight studies $(75 \%)$ that conducted AAT solely in an inside environment showed improvements in depression, agitation, QOL, ADL function, or socioemotional behaviours. One of the studies in which AAT was conducted solely inside found a deterioration in QOL, whilst another found greater levels of agitation. ${ }^{35,41}$ All three studies that reported AAT being conducted both inside and outside showed improvements in QOL, symptoms of dementia, or loneliness. The study which reported conducting AAT solely outside did not report improvements in any measured outcomes. ${ }^{44} \mathrm{~A}$ summary of these findings is presented in Table 5.

The 18 included studies reported AAT sessions being conducted in either individual or group settings. As presented in Table 4, 10 studies utilised AAT in an individual setting and eight conducted AAT in a group setting. Seven of the 10 studies (70\%) conducting sessions in individual settings demonstrated improvements in depression, agitation, QOL, ADL function, and socioemotional behaviours. Two of the eight studies $(25 \%)$ where AAT was conducted in a group setting reported instances of deterioration; one study reported an increase in levels of agitation and another showed an increase in symptoms of dementia. ${ }^{13,41}$ All eight studies (100\%) conducted in a group setting found improvements in depression, QOL, socioemotional behaviours, symptoms of dementia, or loneliness. One study conducted in a group setting showed a decrease in QOL. ${ }^{35}$ AAT conducted in a group setting was associated with a greater likelihood of improvement than AAT conducted in an individual setting.

\section{What Forms of Therapeutic Activities and Interactions Support Effective AAT with Older Adults in Aged Care Facilities?}

Common AAT activities in studies reviewed included physical interaction with, talking to, and walking the dog(s). Only one study did not report on the therapeutic activities involved in the AAT sessions. ${ }^{34}$ As shown in Table 4, physical interaction with the $\operatorname{dog}(\mathrm{s})$ was a feature of all studies that reported on therapeutic activities. These activities included feeding, grooming, patting, cuddling, and/or playing with the dog(s). Physical interaction was a common factor in all AAT interventions in the studies included in this review. Of the 17 studies reporting the use of physical interaction, $14(82.3 \%)$ demonstrated improvements in depression, agitation, QOL, ADL function, socioemotional behaviours, symptoms of dementia, or loneliness. Three of these 17 studies showed deterioration in an outcome. One study reported a decrease in $\mathrm{QOL}^{35}$, another found an increase in agitation ${ }^{41}$, and a third study showed a deterioration in symptoms of dementia. ${ }^{13}$ Eight of the 17 studies involved walking with the dog in conjunction with physical interaction. Six of the eight studies $(75 \%)$ demonstrated improvements in depression, QOL, socioemotional behaviours, symptoms of dementia, or loneliness. One study reported a deterioration relating to agitation. ${ }^{41}$ Eight of the nine studies $(88.9 \%)$ that did not conduct walking with physical interaction showed improvements in depression, agitation, QOL, socioemotional behaviours, or symptoms of dementia. Physical interaction and combined physical interaction and walking were both associated with high rates of positive outcomes. However, it appears that physical interaction without walking may be associated with greater rates of positive outcomes than when in combination with walking.

Across both walking and physical interaction activities, the use of trained/certified dogs appeared more effective than the use of dogs with no reported training. Of the eight studies that utilised walking alongside physical interaction in AAT, five used trained/certified dogs, and three did not report on the training of the dogs. All of the studies that reported using trained/certified dogs demonstrated improvements in depression, QOL, socioemotional behaviours, or symptoms of dementia. None of these five studies reported a deterioration in any outcomes. One of the three studies that did not report dog training reported an improvement in loneliness. ${ }^{38}$ One of these three studies reported a deterioration in agitation. ${ }^{41}$ Studies that reported using walking and physical interaction with trained/certified dogs were associated with a high likelihood of improvements. In contrast, walking and physical interaction with dogs with no reported training was associated with a low likelihood of improvement. 
However, in studies that reported trained/certified dogs, walking in combination with physical interaction was associated with a greater likelihood of positive outcomes than physical interaction alone. Five studies reported using trained/certified dogs with walking as part of AAT. Each of these five studies (100\%) showed an improvement in depression, QOL, socioemotional behaviours, or symptoms of dementia. There were no instances of deterioration in outcomes. Eight studies reported using trained/certified dogs without walking. Seven of these eight studies (87.5\%) demonstrated improvements in depression, agitation, QOL, socioemotional behaviours, or symptoms of dementia. There were two instances of deterioration in studies that did not report dog training/certification. One study showed a decrease in QOL. ${ }^{35}$ The other study demonstrated an increase in symptoms of depression. ${ }^{13}$ Trained/certified dogs were associated with a greater likelihood of improvement when AAT sessions included walking.

\section{DISCUSSION}

The aim of this rapid review was to synthesise existing research evidence to determine the approach(es) that AAT should take to provide effective outcomes for older adults who live in aged care facilities. A literature search, screening, and selection process were conducted. All 18 studies that met the eligibility criteria featured dogs as the animal used in the AAT. Nearly all studies found positive outcomes from the AAT, however several features of AAT were associated with better outcomes.

This review presents findings that contribute to a more detailed understanding of the implementation of effective AAT for older adults in aged care facilities. Previous reviews have established that AAT is beneficial for improving outcomes for older adults in aged care facilities. 3,8 These reviews are valuable as it is important to identify the usefulness of interventions. However, these reviews do not provide information on how the AAT was conducted to ensure feasibility, acceptability, and effectiveness; this information is relevant for health professionals and aged cared facility staff who might wish to implement AAT. This rapid review builds on previous research by synthesising existing evidence to draw conclusions that can inform health professionals and aged care facility staff on how effective AAT can be implemented to improve outcomes for older adults in aged care facilities.

Several findings of importance were identified in this review. AAT was effective at improving depression and socioemotional behaviours in all studies that measured depression or depressive symptoms, regardless of the frequency, session duration or overall intervention period. AAT most frequently resulted in improvements in QOL when sessions were conducted twice weekly, or 1-2 times weekly. AAT that included physical interaction, such as feeding, grooming, patting, cuddling, and/or playing with the $\operatorname{dog}(\mathrm{s})$, without additional walking was associated with the highest likelihood of positive outcome. Interestingly, AAT with physical interaction and walking was associated with positive outcomes to a greater extent when trained/certified therapy dogs were used. Generally, the use of trained/certified therapy dogs was more likely to improve participant outcomes than studies that used dogs with no reported training. AAT organisation provided facilitators, solely nursing, and veterinary trained facilitators were associated with the greatest likelihood of positive outcomes. However, solely nursing and veterinary trained facilitators were only included in one study each, limiting the confidence of conclusions about their effectiveness. AAT conducted in a group setting was associated with the highest likelihood of improved outcomes. AAT conducted in a combined inside/outside environment was associated with the highest likelihood of improved outcomes, followed by solely indoors. Only one study was conducted solely outdoors, limiting conclusions that can be drawn about this setting.

It is common for older adults in aged care facilities to have poor socioemotional health, and depression and/or depressive symptoms. ${ }^{47}$ The results of this rapid review suggest that AAT may be a valuable strategy to address these issues. The findings of this review also suggest that AAT of many frequencies, session durations, and overall intervention periods could be effective in improving residents' depressive symptoms and socioemotional health. This finding is useful for staff and managers in aged care facilities as it demonstrates that AAT does not necessarily require a significant time commitment to be effective, increasing the feasibility of AAT intervention. For example, an AAT intervention as short as two 10-minute sessions per week for six weeks could be effective in improving symptoms of depression. ${ }^{13}$ However, if the aim of AAT intervention is to improve older adults' QOL, which is also commonly low in aged care facilities, the session frequency should be considered. ${ }^{3}$ The results of this review suggest that for positive QOL outcomes, AAT sessions should occur up to twice a week. 22,35,37

The common factor evident in successful AAT research interventions appears to be physical interaction with the dog(s) including feeding, grooming, patting, cuddling, and/or playing with them. This physical interaction may enhance the likelihood of improvements in participant outcomes. AAT that involved walking in addition to physical interaction also demonstrated a high likelihood of positive outcomes in older adults living in aged care facilities - particularly when trained dogs were used. As both physical interaction and combined physical interaction and walking were associated with high likelihood of positive outcomes, it is worth considering the potential additional benefits of walking on aspects of health and wellbeing that may not have been measured in the AAT studies included in this review (e.g. fitness and functional capacity), or were only measured in some (e.g. falls risk). ${ }^{48}$ Additionally, the company of a dog may motivate older adults to engage in walking activities that they otherwise might not engage in. ${ }^{49}$ This is important because older adults living in aged care facilities are typically physically inactive. ${ }^{50,51}$ 
It is suggested that trained/certified therapy dogs should be used for AAT where possible. In addition, this review found that AAT conducted by facilitators with solely veterinary or nursing training resulted in an improvement in loneliness and depression, respectively. Some form of AAT training demonstrated a high likelihood of improved participant outcomes (70\%). The lowest likelihood of improved outcomes was associated with AAT using facilitators with a combination of training types $(66.7 \%)$. However, caution is warranted as only one study included in this review used a facilitator with solely veterinary training and only one used a facilitator with solely nursing training; the single instances of these two training types limited the data available for synthesis and reduces the confidence with which any conclusions can be made about the link between veterinary or nursing training and positive outcomes. Therefore, aged care staff and managers are encouraged to utilise trained facilitators, or seek AAT training for facilitators, to increase the likelihood of positive outcomes for older adults.

There was some evidence to suggest that AAT conducted in combined indoor/outdoor, or solely indoor settings was associated with greater effectiveness of AAT as compared with AAT conducted outdoors only. However, this finding may be inconclusive as this review included a small number of studies that involved indoor only or outdoor only settings. Additionally, the only study that reported outdoor AAT was a single participant case study, further limiting the generalisability of this study's findings ${ }^{44}$ To enable rigorous comparisons, further AAT research is required in purely indoor and purely outdoor settings. Without adequate evidence to draw confident conclusions regarding AAT in indoor and outdoor settings, it is suggested that the setting be chosen according to the needs of the aged care facility and the residents. For example, if indoor spaces are not large enough or longer dog walks are planned, then outdoor settings are appropriate; if it is raining or resident mobility is significantly restricted, then indoor spaces are more likely to be appropriate.

Based on the findings of this review, it is recommended that AAT be performed in groups. Older adults in aged care facilities can be socially isolated and feel lonely. ${ }^{2}$ It may be that increased social connection with other people, as well as with the dog(s), contributed to the positive outcomes found in group AAT settings. Group therapy may not only increase the likelihood of effectiveness in comparison to AAT in individual settings, but also increase the feasibility of AAT by reducing the time commitment of staff and cost involved.

Although the approaches discussed above may reflect the best available evidence, it is also important for AAT to be feasible and accessible to aged care facilities. If facilities do not have access to trained dogs or facilitators, AAT can still be conducted with untrained facilitators and untrained dogs, but it is possible that the effectiveness of the intervention will be limited. It is also beneficial for aged care facility staff and managers to be aware that AAT can be conducted using a range of therapeutic activities. It is important to note that some aged care facilities may not have the capacity to include certain activities, such as dog walking, as part of an AAT program due to resident activity level or space restrictions. In these instances, it is recommended that AAT be incorporated into activities where there is capacity to implement within the setting, and that residents be offered the opportunity to engage in activities they have capacity for, such as patting, grooming or treating the dog. These approaches may increase the feasibility of AAT in aged care facilities.

It is worth noting that three of the outcomes measured - QOL, agitation and symptoms of dementia - were found to vary between the 18 included studies. In some studies, these outcomes were positively impacted and in others they were negatively impacted. One study that measured QOL found mixed results. In this study, QOL was measured in three separate facilities, where a positive outcome was found in the first facility, no significant outcome was found in the second, and a negative outcome was found in the third. QOL was shown to improve in a further three studies. Agitation improved in two studies and deteriorated in a third. Symptoms of dementia also improved in two studies and worsened in another. These conflicting outcomes could be due to the small sample sizes used in the included studies or other factors that impacted these outcomes throughout the duration of the studies.

The current rapid review makes significant contributions to the growing field of AAT research. Previous reviews have explored factors, such as environmental supports, and individual needs and preferences, that influence the outcomes of AAT related to QOL or have addressed the evidence regarding effects of AAT on elderly patients with dementia and/or psychiatric disorders ${ }^{3,8}$ However, these reviews have not examined the specific aspects of AAT in a way that is useful for health professionals considering the implementation of AAT. Although past reviews have included primary articles containing information about how AAT was implemented in the study or detailed intervention plans, these aspects were not summarised or analysed to determine what aspects of the AAT supported effective intervention. ${ }^{3,8}$ The current rapid review has addressed this gap in the literature.

\section{Limitations}

The current rapid review has identified several weaknesses in existing research literature, and it is recommended that future research should aim to address these limitations. Existing studies on AAT for older adults in aged care facilities varied greatly in the outcomes they assessed. Even when studies assessed the same outcomes, they used different measures. This makes comparisons of the effectiveness of AAT difficult. Therefore, future research in AAT should aim to use common, standardised measures to enable more meaningful comparisons. Some assessments commonly used in the included studies were the 
GDS, QUALID and the CMAI. Assessments such as these are recommended for use in future research as they assess important outcomes and have good reliability and validity. ${ }^{53-56}$ Another weakness of existing research is that it is limited in terms of the number of studies that utilised exclusively indoor and exclusively outdoor settings; and veterinary or nursing trained facilitators. Future research should address these gaps so that fair comparisons can be made about the setting of AAT and appropriate facilitator training. Future primary and secondary research on AAT should report all the details of AAT implemented in primary research studies. Reports should include details of the frequency, duration, intervention period length, facilitator training, animals used and training, environment/setting and the therapeutic activities involved. If future research provides these details, it could support practitioners to more readily make decisions that result in effective implementation of AAT. Such details would facilitate determination of AAT implementation recommendations. The current review aimed to identify different animals that were associated with positive outcomes in AAT. Past research has involved AAT being conducted with animals other than dogs. However, studies using dogs were the only articles to progress through the inclusion process in the current review. Further high-quality research is required with animals other than dogs to determine if and why they are effective at improving participant outcomes. Future research may identify other animals that are effective to use in AAT for older adults in aged care facilities. Identifying other animals to use in AAT provides greater choice for aged care facility managers and staff when implementing AAT. Importantly, the use of different types of animals in AAT may provide greater choice for participants and increased opportunities to reminisce as many people have had pets other than dogs.

The above identified limitations in the research literature restrict the confidence of conclusions that can be drawn from this current review. The limited number of studies which included exclusively indoor and exclusively outdoor settings, and solely veterinary or solely nursing trained facilitators means that conclusions about these aspects of AAT are not conclusive. This study focused on AAT aspects that were likely to be effective and had been synthesised from a larger number of studies, such as indoor/outdoor combined settings and AAT specific training. Although this focus is sound given the current, limited literature, future research targeting these gaps would be useful to provide evidence about the effectiveness of these aspects of AAT. In addition, the variation in assessed outcomes and the measures used to assess those outcomes limited what this rapid review could conclude from the literature. Another limitation of this review is that it only focused on quantitative research, potentially excluding useful qualitative data about effective features of AAT. Future reviews may benefit from also examining qualitative or mixed methods research. This review also assumed that studies that did not report dog training used untrained dog(s). Dogs may have been trained, but this may simply not have been reported. However, the difference in the likelihood of effectiveness between AAT with reportedly trained dogs and AAT with dogs with no reported training suggests that these dogs may have been different in some way. Future research should specify the training, or lack thereof, of the animals used in AAT. Finally, another limitation of this review is that only studies published in English were considered for inclusion.

\section{Conclusion}

The findings of this review indicate that AAT involving dogs was typically associated with positive outcomes for older adults living in residential care, however, some features of AAT were associated with better outcomes. For AAT to be most effective in addressing a range of key outcomes in older people in aged care facilities, it should, where possible: be implemented up to twice a week to improve QOL; be implemented in a group setting; include physical interaction with the dog(s), which may include walking with the $\operatorname{dog}(\mathrm{s})$; involve trained/certified dogs; and include facilitators provided by AAT organisations, or facilitators with veterinary, nursing or some form of AAT training. To optimise outcomes, health professionals and aged care facility staff should consider these aspects of AAT when considering the implementation of AAT for older adults at an aged care facility.

\section{REFERENCES}

1. Cipriani J, Cooper M, DiGiovanni NM, Litchkofski A, Nichols AL, Ramsey A. Dog-assisted therapy for residents of long-term care facilities: an evidence-based review with implications for occupational therapy. Physical \& Occupational Therapy in Geriatrics. 2013;31(3):214-240.

2. Lai NM, Chang SMW, Ng SS, Stanaway F, Tan SL, Chaiyakunapruk N. Animal-assisted therapy for dementia. Cochrane Database of Systematic reviews. 2019(1).

3. Wood W, Fields B, Rose M, McLure M. Animal-assisted therapies and dementia: a systematic mapping review using the lived environment life quality (LELQ) model. The American Journal of Occupational Therapy.

2017;71(5):1-10.

4. Ebener J, Oh H. A Review of Animal-assisted interventions in long-term care facilities. Activities, Adaptation \& Aging. 2017;41(2):107-128.

5. Stern C, Pearson A, Am Rn ONC, et al. The appropriateness of canine-assisted interventions (CAls) on the health and social care of older people residing in long term care: a systematic review. JBI Libr Syst Rev. 2011;9(33):1367-1392.

6. Yakimicki ML, Edwards NE, Richards E, Beck AM. animal-assisted intervention and dementia: a systematic review. Clinical Nursing Research. 2018;28(1):9-29. 
7. Baun M, Johnson R. 15 - Human/animal interaction and successful aging. In: Fine AH, ed. Handbook on animalassisted therapy (3rd Ed). San Diego: Academic Press; 2010:283-299.

8. Peluso S, De Rosa A, De Lucia N, et al. Animal-assisted therapy in elderly patients: evidence and controversies in dementia and psychiatric disorders and future perspectives in other neurological diseases. Journal of Geriatric Psychiatry and Neurology. 2018;31(3):149-157.

9. Lefebvre SL, Golab GC, Christensen EL, et al. Guidelines for animal-assisted interventions in health care facilities. American Journal of Infection Control. 2008;36(2):78-85.

10. Marino L. Construct validity of animal-assisted therapy and activities: how important is the animal in AAT? Anthrozoös. 2012;25(sup1):s139-s151.

11. Homnick TD, Henning KM, Swain CV, Homnick DN. The effect of therapeutic horseback riding on balance in community-dwelling older adults: a pilot study. Journal of Applied Gerontology. 2015;34(1):118-126.

12. Olsen C, Pedersen I, Bergland A, Enders-Slegers M-J, Ihlebæk C. Effect of animal-assisted activity on balance and quality of life in home-dwelling persons with dementia. Geriatric Nursing. 2016;37(4):284-291.

13. Thodberg K, Sørensen LU, Christensen JW, et al. Therapeutic effects of dog visits in nursing homes for the elderly. Psychogeriatrics. 2016;16(5):289-297.

14. O'Rourke PP, Niemi SM, Palley LS. Mainstreaming animal-assisted therapy. ILAR Journal. 2010;51(3):199-207.

15. Scheibeck R, Pallauf M, Stellwag $C$, Seeberger S. Elderly people in many respects benefit from interaction with dogs. Eur J Med Res. 2011;16(12):557-563.

16. Pope W, Hunt C, Ellison K. Animal assisted therapy for elderly residents of a skilled nursing facility. Journal of Nursing Education and Practice. 2016;6(9).

17. Majic T, Gutzmann H, Heinz A, Lang UE, Rapp MA. Animal-assisted therapy and agitation and depression in nursing home residents with dementia: a matched case-control trial. American Journal of Geriatric Psychiatry. 2013;21(11):1052-1059.

18. Sunderland T, Hill JL, Lawlor BA, Molchan SE. NIMH Dementia Mood Assessment Scale (DMAS). Psychopharmacol Bull. 1988;24(4):747-753.

19. Consedine NS, Magai C, Krivoshekova YS. Sex and age cohort differences in patterns of socioemotional functioning in older adults and their links to physical resilience. Ageing International. 2005;30(3):209-244.

20. Ebner N, Maura G, Macdonald K, Westberg L, Fischer H. Oxytocin and socioemotional aging: current knowledge and future trends. Frontiers in Human Neuroscience. 2013;7(487).

21. Rondón García LM, Ramírez Navarrro JM. The impact of quality of life on the health of older people from a multidimensional perspective. Journal of Aging Research. 2018;2018:4086294-4086294.

22. Olsen C, Pedersen I, Bergland A, Enders-Slegers MJ, Patil G, Ihlebæk C. Effect of animal-assisted interventions on depression, agitation and quality of life in nursing home residents suffering from cognitive impairment or dementia: a cluster randomized controlled trial. International Journal of Geriatric Psychiatry. 2016;31(12):13121321.

23. Klimova B, Toman J, Kuca K. Effectiveness of the dog therapy for patients with dementia - a systematic review. BMC Psychiatry. 2019;19(1):276.

24. Moher D, Liberati A, Tetzlaff J, Altman DG, The PG. Preferred reporting items for systematic reviews and metaanalyses: the PRISMA statement. PLOS Medicine. 2009;6(7):e1000097.

25. Tricco AC, Antony J, Zarin W, et al. A scoping review of rapid review methods. BMC Medicine. 2015;13(1):224.

26. Munn Z, Aromataris E, Tufanaru C, et al. The development of software to support multiple systematic review types: the Joanna Briggs Institute system for the unified management, assessment and review of information (JBI SUMARI). International Journal of Evidence-Based Healthcare. 2019;17(1):36-43.

27. Clarivate Analytics. EndNote. Version X8.2 [software]. 2019 [cited 2020 Oct 1] Available from: https://endnote.com/license. Published 2019. Accessed.

28. The University of Adelaide. Critical Apprasial Tools. Available from: https://joannabriggs.org/critical-appraisal-tools. Published Undated. Accessed.

29. The National Health and Medical Research Council. National statement on ethical conduct in human research 2007 (updated 2018). Canberra: National Health and Medical Research Council (NHMRC); 2007.

30. Lisy K, Porritt K. Narrative Synthesis: Considerations and challenges. International Journal of Evidence-Based Healthcare. 2016;14(4):201.

31. Tacconelli E. Systematic reviews: CRD's guidance for undertaking reviews in health care. The Lancet Infectious Diseases. 2010;10(4):226.

32. Popay J, Roberts H, Sowden A, et al. Guidance on the conduct of narrative synthesis in systematic reviews: a product from the ESRC Methods Programme. 2006.

33. Ambrosi C, Zaiontz C, Peragine G, Sarchi S, Bona F. Randomized controlled study on the effectiveness of animalassisted therapy on depression, anxiety, and illness perception in institutionalized elderly. Psychogeriatrics. 2019;19(1):55-64.

34. Briones MÁ, Pardo-García I, Escribano-Sotos F. Effectiveness of a dog-assisted therapy program to enhance quality of life in institutionalized dementia patients. Clinical Nursing Research. 2019. 
35. Travers $\mathrm{C}$, Perkins J, Rand J, Bartlett H, Morton J. An evaluation of dog- assisted therapy for residents of aged care facilities with dementia. Anthrozoos. 2013;26(2):213-225.

36. Friedmann E, Galik E, Thomas SA, Hall PS, Chung SY, McCune S. Evaluation of a pet-assisted living intervention for improving functional status in assisted living residents with mild to moderate cognitive impairment: a pilot study. American Journal of Alzheimer's Disease \& Other Dementias®. 2014;30(3):276-289.

37. Nordgren L, Engström G. Animal-assisted intervention in dementia: effects on quality of life. Clinical Nursing Research. 2014;23(1):7-19.

38. Vrbanac Z, Zecevic I, Ljubic M, et al. Animal assisted therapy and perception of loneliness in geriatric nursing home residents. Collegium antropologicum. 2013;37(3):973-976.

39. Tournier I, Vives M-F, Postal V. Animal-assisted intervention in dementia: effects on neuropsychiatric symptoms and on caregivers' distress perceptions. Swiss Journal of Psychology / Schweizerische Zeitschrift für Psychologie. 2017;76(2):51-58.

40. Wesenberg S, Mueller C, Nestmann F, Holthoff-Detto V. Effects of an animal-assisted intervention on social behaviour, emotions, and behavioural and psychological symptoms in nursing home residents with dementia. Psychogeriatrics. 2019;19(3):219-227.

41. Nordgren L, Engström G. Effects of dog-assisted intervention on behavioural and psychological symptoms of dementia. Nursing Older People. 2014;26(3):31-38.

42. Moretti F, De Ronchi D, Bernabei V, et al. Pet therapy in elderly patients with mental illness. Psychogeriatrics. 2011;11(2):125-129.

43. Berry A, Borgi M, Terranova L, Chiarotti F, Alleva E, Cirulli F. Developing effective animal-assisted intervention programs involving visiting dogs for institutionalized geriatric patients: a pilot study. Psychogeriatrics. 2012;12(3):143-150.

44. Nordgren L, Engstrom G. Effects of Animal-Assisted Therapy on Behavioral and/or Psychological Symptoms in Dementia: A Case Report. American Journal of Alzheimer's Disease \& Other Dementias. 2012;27(8):625-632.

45. Swall A, Fagerberg I, Ebbeskog B, Hagelin C. A therapy dog's impact on daytime activity and night-time sleep for older persons with Alzheimer's disease - a case study. Clinical Nursing Studies. 2014;2.

46. Kårefjärd A, Nordgren L. Effects of dog-assisted intervention on quality of life in nursing home residents with dementia. Scandinavian Journal of Occupational Therapy. 2019;26(6):433-440.

47. Davison TE, McCabe MP, Mellor D, Ski C, George K, Moore KA. The prevalence and recognition of major depression among low-level aged care residents with and without cognitive impairment. Aging \& Mental Health. 2007;11(1):82-88.

48. Voukelatos A, Merom D, Rissel C, Sherrington C, Watson W, Waller K. The effect of walking on falls in older people: the 'Easy Steps to Health' randomized controlled trial study protocol. BMC Public Health. 2011;11(888). doi:10.1186/1471-2458-11-888

49. Johnson RA, Meadows RL. Dog-walking: motivation for adherence to a walking program. Clinical Nursing Research. 2010;19(4):387-402.

50. Douma JG, Volkers KM, Engels G, Sonneveld MH, Goossens RHM, Scherder EJA. Setting-related influences on physical inactivity of older adults in residential care settings: a review. BMC geriatrics. 2017;17(1):97-97.

51. Palese A, Del Favero C, Antonio Zuttion $R$, et al. Inactive residents living in nursing homes and associated predictors: findings from a regional-based, italian retrospective study. Journal of the American Medical Directors Association. 2016;17(12):1099-1105.

52. Brownie $S$, Horstmanshof $L$. The management of loneliness in aged care residents: an important therapeutic target for gerontological nursing. Geriatric Nursing. 2011;32(5):318-325.

53. Massai $P$, Colalelli F, Sansoni J, et al. Reliability and validity of the Geriatric Depression Scale in Italian subjects with Parkinson's disease. Parkinsons Dis. 2018;7347859. doi:10.1155/2018/7347859

54. Resnick B, Galik E, Kolanowski A, et al. Reliability and validity testing of the quality of life in late-stage dementia scale. American Journal of Alzheimer's Disease \& Other Dementias. 2018;33(5):277-283.

55. Finkel SI, Lyons JS, Anderson RL. Reliability and validity of the Cohen-Mansfield agitation inventory in institutionalized elderly. International Journal of Geriatric Psychiatry. 1992;7(7):487-490.

https://doi.org/10.1002/gps.930070706 